Florida International University FIU Digital Commons

FIU Electronic Theses and Dissertations

University Graduate School

$1-18-2017$

\title{
Social Networks, Health \& Hispanic Gay Men Living in South Florida
}

Victor Christian Vila

Florida International University, vvila001@fiu.edu

DOI: $10.25148 /$ etd.FIDC001779

Follow this and additional works at: https://digitalcommons.fiu.edu/etd

Part of the Community-Based Research Commons, Developmental Psychology Commons, Gender and Sexuality Commons, Gerontology Commons, Health Psychology Commons, Race and Ethnicity Commons, Social Psychology Commons, and the Sociology of Culture Commons

\section{Recommended Citation}

Vila, Victor Christian, "Social Networks, Health \& Hispanic Gay Men Living in South Florida" (2017). FIU Electronic Theses and Dissertations. 3194.

https://digitalcommons.fiu.edu/etd/3194

This work is brought to you for free and open access by the University Graduate School at FIU Digital Commons. It has been accepted for inclusion in FIU Electronic Theses and Dissertations by an authorized administrator of FIU Digital Commons. For more information, please contact dcc@fiu.edu. 


\title{
FLORIDA INTERNATIONAL UNIVERSITY
}

Miami, Florida

\section{SOCIAL NETWORKS, HEALTH \& HISPANIC GAY MEN LIVING IN SOUTH FLORIDA}

\author{
A thesis submitted in partial fulfillment of the \\ requirements for the degree of \\ MASTERS OF SCIENCE \\ in \\ PSYCHOLOGY \\ by \\ Victor Christian Vila
}

2017 
To: Dean Michael R. Heithaus

College of Arts, Sciences and Education

This thesis, written by Victor Christian Vila, and entitled Social Networks, Health \& Hispanic Gay Men Living in South Florida, having been approved in respect to style and intellectual content, is referred to you for judgment.

We have read this thesis and recommend that it be approved.

Leslie Frazier

Eric Fenkl

Dionne Stephens, Major Professor

Date of Defense: January 18, 2017

The thesis of Victor Christian Vila is approved.

Dean Michael R. Heithaus
College of Arts, Sciences and Education

College of Arts, Sciences and Education

Andrés G. Gil

Vice President for Research and Economic Development and Dean of the University Graduate School

Florida International University, 2017 


\title{
ABSTRACT OF THE THESIS
}

\section{SOCIAL NETWORKS, HEALTH \& HISPANIC GAY MEN LIVING IN SOUTH}

FLORIDA

\author{
by \\ Victor Christian Vila \\ Florida International University, 2017 \\ Miami, Florida \\ Professor Dionne Stephens, Major Professor
}

Aging Hispanic populations are expected to increase in the United States (U.S.) to 21.5 million by 2060 according to the National Council on Aging (NCA) (2014). Although actual estimates vary, Gates (2013) asserts that over one million Hispanics identify as gay or bisexual and their unique needs must be explored (Clover, 2006; Cohn \& Taylor, 2010; Fenk1, 2014). Unfortunately, few studies examine aging Hispanic men who identify as gay or bisexual according to the National Hispanic Council on Aging (NHCOA) (2013). The objective of the current study was to extend the limited research on aging gay/bisexual men in the southeastern U.S. (e.g., Fenkl, 2014) by focusing on Hispanic gay/bisexual men in South Florida. The current study identifies social networks that serve to help this population's health and well-being concerns related to aging. Findings from the 20 male participants in the current study provided evidence that there are unique health concerns associated with aging within this population. The current project has the potential to help health care providers, social service providers and policy makers, with an increased understanding of the special needs and challenges experienced by aging gay ethnic minorities in communities throughout the U.S. 


\section{TABLE OF CONTENTS}

CHAPTER

PAGE

I. INTRODUCTION .1

Health, Aging and Hispanic Gay Men: An Introduction .........................................................

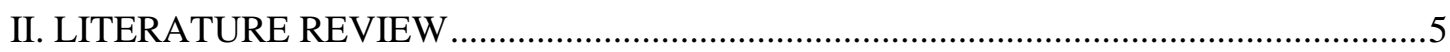

Social Networks, Health and Aging...................................................................................

Social Network Theory …………………………………………………………...

Social Networks and Individual Level Considerations ..........................................................9

Gender Considerations ............................................................................................

Racial/Ethnicity Considerations.........................................................................................11

Sexual Orientation Considerations .................................................................................12

Social Networks and Aging Hispanic Gay Men ................................................................. 14

Current Study …………………………………………………………………17

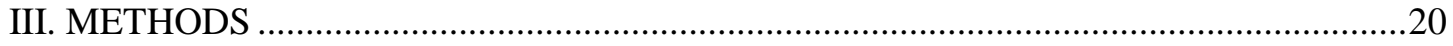

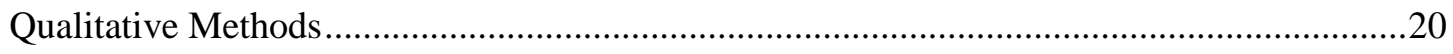

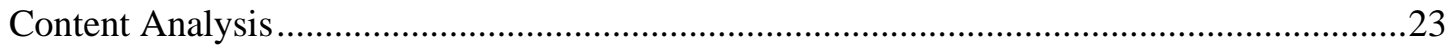

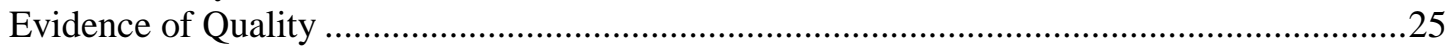

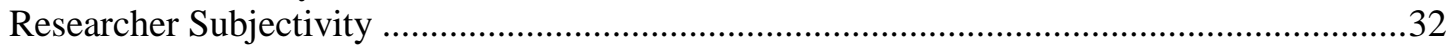

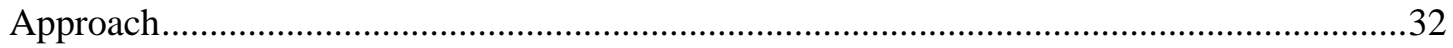

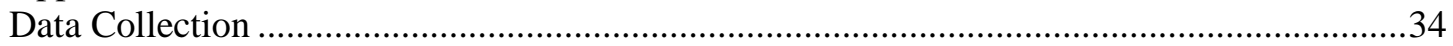

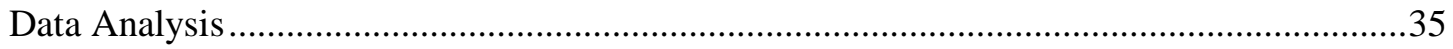

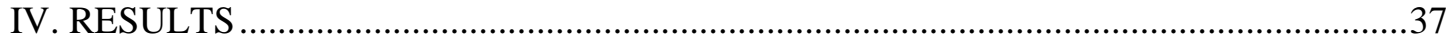

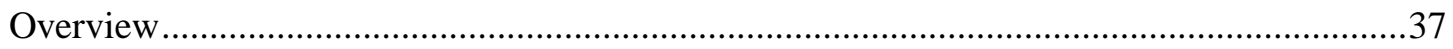

Demographic Profiles …………………………………………………………………38

Aging Related Health Concerns.....................................................................................38

Current Health Social Networks ....................................................................................4

Desired Health Social Networks .......................................................................................

Other Aging Related Social Network Concerns …………………………………………......61

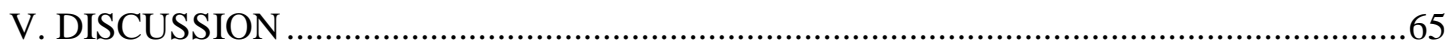

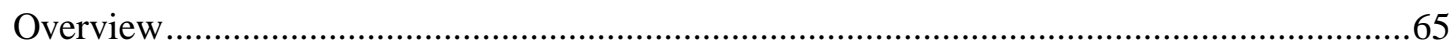

Aging Related Health Concerns.........................................................................................6

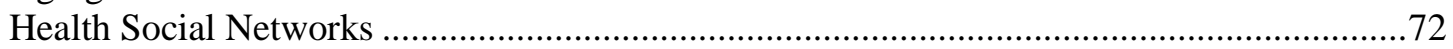

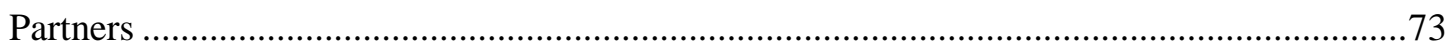

Family and Close Friends ..........................................................................................

Health Care Providers...................................................................................................

Gay Community Spaces............................................................................................

Other Aging Related Social Network Concerns ………………………………………......

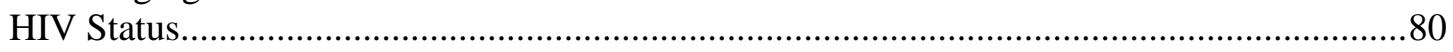

Homophobia in the Hispanic Community ..................................................................... 81

Racism in the Gay Community ……………………………………………………..... 82

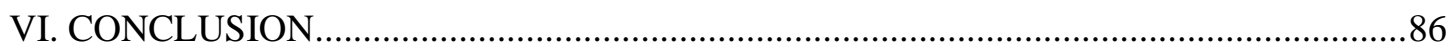

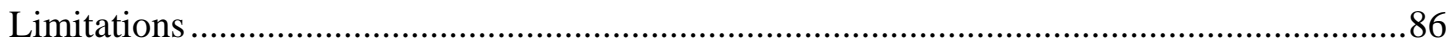




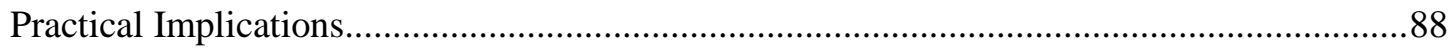

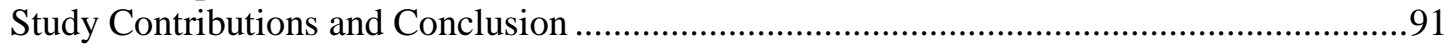

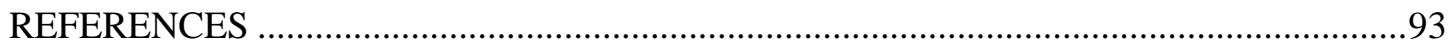

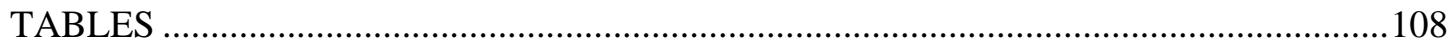

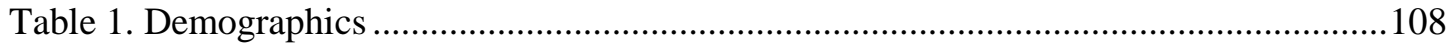

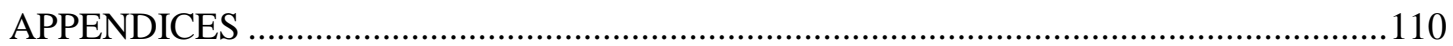




\section{INTRODUCTION}

\section{Health, Aging and Hispanic Gay Men: An Introduction}

Every day, 10,000 Americans turn 65, thus entering the pool of 26 percent of older adults that make up the population in the United States (U.S.) (Cohn \& Taylor, 2010). People ages 65 and older are the fastest growing population in the U.S. (Miller, 2014). However, there is little evidence to suggest that older people today are experiencing their later years in better physical or psychological health than their parents (Chang, Wray, \& Lin, 2014). The extent of people's quality of life as one ages depends heavily on one's health (Chang, Wray, \& Lin, 2014; Sneed \& Cohen, 2014). For example, among mature adults ages 55 and older, about 92 percent have at least one chronic health condition while 77 percent have at least two according to the National Council on Aging (NCA) (2014).

One key factor in ensuring older adults remain healthy is having regular positive interactions with social networks (Chang, Wray, \& Lin, 2014; Sneed \& Cohen, 2014; Wu, 2004). Specifically, having family and friends, and being involved in several different social networks has been found to increase live longevity and over all physical and psychological well-being (Marquez et al., 2014 Sneed \& Cohen, 2014; Wu, 2004). Researchers have cautioned that it is not enough to simply look at the health experiences of America's older population as homogenous, as certain groups that experience health because of differing identities, including race/ethnicity, social economic status, geographic region, acculturation, and gender. For example, Hispanic people account for 3.6 million in 2014 among the growing elderly in the U.S. and the group is expected to increase to 21.5 million by 2060 (NCA, 2014). Research has 
noted that while that the Hispanic population is at risk for several negative health outcomes, they are more likely to have supportive familial and community social networks that can help them negotiate health care concerns (Eschbach et al., 2004; Markides, Angel, Peek, 2013; Marquez et al., 2014). Furthermore, having a religious social network that is linked to one's familial support systems increases the psychological well-being of older Hispanics in many communities, a trend not found across other racial/ethnic groups (Reyes-Ortiz et al. 2006; Reyes-Ortiz et al. 2006)

Similarly, members of the LGBT community are facing unique social networking concerns linked to aging in today's society. Some studies have noted that LGBT individuals are emotionally taxed when they address personal aging concerns with others when they have not disclosed their orientation/gender identity (Higgins, Sharek, \& Glacken, 2016; McParland \& Camic, 2016; Erdley, Anklam, \& Reardon, 2014). Also, there are issues within group differences as Schope (2005) discusses in that gay men have more negative views of how gay society views growing older; and how they view their own growing older than do lesbian respondents. Taken together, the ways in which age-related health and social network concerns are addressed among diverse aging populations will differ greatly.

Among groups that are growing in numbers in the U.S. are racial/ethnicminority lesbian, gay, bisexual and transgender (LGBT) populations (Almaguer 1991; Garcia, 1998; Gates, 2013; Kurtz, 1999; Reisen, 2010; Vega, 2011). Given the growth of aging Hispanics, researchers note that the number of LGBT identified Hispanics is growing and is expected to become one of the largest racial/ethnic-minority populations within that community (Diaz, 2013). However, only a limited number of 
studies have explored the aging experiences of older Hispanic gay men (NHCOA, 2013). This is concerning as it has been found that at this stage of the lifespan Hispanic gay men are at risk for experiencing increased social isolation, and financial burdens, simultaneous to decreased autonomy, agency and social support (North \& Fiske, 2012; Stone \& McMinn, 2012). Clearly there is a need to explore these issues given the projected increase in the number of aging men identifying as gay and Hispanic.

The current study addresses this void in the research by specifically exploring the issues of health disparities and social support within this population. The current study examines the social networks that help and hinder older gay Hispanic men's aging experiences and well-being. Specifically, the current study identifies social relationship structures, functions, and quality, to understand their association with well-being around aging concerns in this population. The current study employed qualitative methods, as this approach provides rich description and special access to the lives of individuals (Babbie, 2005; Berg, 2006; Charmaz, 2006; Fenkl, 2014). Through the use of individual interviews two guiding research questions were examined:

1) What social networks do older Hispanic gay men perceive as having an influence on their health and aging experiences?, and

2) How do these social networks help and/ or hinder older Hispanic gay men's ability to address these factors influencing their health and aging experiences? 
The current study recruited a sample of 20 men between the ages of 50 to 70 years of age, who self- identified as gay or bisexual and who identify as Hispanic. These findings have the potential to help health care providers, social service providers with an improved, culturally sensitive understanding of the special needs of aging gay ethnic minorities in communities throughout the U.S. Gaining a better understanding of these unique racial/ethnic risk factors, experiences and related sociohistorical factors will improve the quality of treatment and quality of life for aging minority groups into older age. Further, it will provide important insight for health care providers, social service providers and policy makers to better prepare for the forthcoming demands of these changing demographics in the U.S. 


\section{LITERATURE REVIEW}

\section{Social Networks, Health and Aging}

The increase in the number of elderly in the U.S. poses many challenges and considerations for health care providers, policy makers, the elderly people themselves, and the general community (Fenkl, 2014; Miller, 2014). Of particular importance are ethnic/racial and sexual minority populations who will be in need of culturally competent social networks for support (Afable-Munsuz et al, 2013; Ahmad \& Bhurgra, 2010; Al Hazzoiuri et al, 2011; Kim, et al, 2009; Rosenfeld et al., 2008). Until recently, Whites dominated the nation's retirees, accounting for 84 percent of those older than 65 in 2000 . By 2050, they will represent a slight majority at 58 percent (Census, 2015). Hispanics are expected to account for nearly 20 percent of those older than 65 by that time, which is four time their percentage today (Census, 2013).

Among the growing number of elderly people in the U.S. a significant number also identify as gay and lesbian (Fenkl, 2014; Gates, 2011; Rosenfeld et al., 2008). Estimates of the gay and lesbian population vary widely; according to Fenkl (2014) there are four million people in the U.S. who identify as gay and lesbian while according to Gates (2011) there are nine million gay and lesbian people living in the U.S. National data on racial/ethnic-minority subgroups are limited due to stigmas and cultural values associated with sexual identity issues (Green, 2008; Guzman, 2005; Kurtz, 1999; Moraga, 1993; Peralta et al., 2013; Vega, 2011). According to Gates (2013) there are over one million Hispanics who identify as gay and lesbian in the U.S. Given the size of the Hispanic gay and lesbian population in the U.S. requires that more research be conducted to address their unique needs. 
What is known is that the majority of same-sex partner households in the U.S. are White, aged 65 and over, with 49 percent earning between $\$ 100,000$ or higher annually (Census, 2013). This information does not present an accurate picture, however, as other studies have noted that the majority of LGBT people (51\%) struggle with job insecurity, retirement planning and basic needs like food, housing and medical care (Albeda et al., 2009). Further, the Centers for Disease Control (CDC, 2014) reports that men who have sex with men are among the highest of reported cases of HIV/AIDS infection rates in the U.S., which adds yet another layer of complexity to their lives.

It is important to note that aging gay men share experiences of having lived through the worst of the HIV/AIDS epidemic in during the years 1987-1996 (Johnson, 1992; Rupp, 1999; Jay, 2000; Dworkin \& Yi, 2003; Mayer, et al., 2008; Fenkl, 2014). Research has shown that this cohort experience has had a profound psychological and social effect on their perceptions of health and social networks supports (Ahmad \& Bhugra, 2010; Alden \& Parker, 2005; Hansson, 1990; Herek \& Garnets, 2007; Rosenfeld et al., 2008). Many of their cohort simply vanished before them during the time they were growing up or coming of age as young gay men (Rosenfeld et al., 2008) leaving lasting psychological scars. For many gay men and especially aging men, the importance of social networks is paramount. Research has noted that supportive social networks have multiple benefits to health and decreasing risky behaviors and HIV/AIDS infection risk, condom use and seeking medical attention to manage HIV infection (Briane et al., 2011; Fergus \& Darbes, 2009; Green, 2008; Purdie-Vaughns \& Eibach, 2008). 


\section{Social Network Theory}

To fully understand how these social networks work, social network theory or SNT was employed to better understand and gain access into these social networks (Berkman, 2002; Berkman \& Glass, 2002; Simons- Morton Haynie \& Noelcke, 2009). As a framework, SNT addresses how relationships between people influence health communications, SNT can help researchers identify the ways in which these relationships build connections between individuals, allow for the exchange of information, or provide space for more tangible exchanges of resources (e.g., assistance with living expenses, health insurance). In the context of the present study, SNT was crucial in identifying what social networks and who within these networks influence Hispanic gay men in the negotiation of aging related health experiences.

The concept of a social network is defined as the social structure of interconnections and relationships which surround an individual, group or organization that influences behavior, social arrangements and world view (Berkman, 2002; SimonsMorton Haynie \& Noelcke, 2009). Social network theory states that the relationships and connections between an individual and various social networks have a strong impact on influencing the behavior and self-concept of the individual. Social network theory offers an organized perspective of categorizing and rating the degree of influence thus allowing increased understanding of these connections. Identifying these networks and social connections is critical in understanding the degree of influence on the individual. Moreover, individuals often belong to multiple social networks, each having a degree of influence, which makes SNT ideal in mapping out the myriad networks to which an individual belongs. Smaller social groups which have immediate impact are families and 
peers, which in turn have connections to larger social groups and institutions (e.g., education, religion, health systems or media) (Berkman, 2002; Berkman \& Glass, 2002).

Social network theory asserts that social networks contain various levels of influence which engage the individual though the process of socialization, selection and social norms. Socialization is a complex process orchestrated through multiple social networks which educates the individual how to think, behave and feel (Simons-Morton Haynie \& Noelcke, 2009). The socialization processes is both direct and indirect in the way it educates the individual where those behaviors that reinforce the consistency of the particular value system of a network.

However, the manner in which an individual processes these social cues varies and one may accept or reject these through the process of selection. Social network theory asserts that an individual does not accept or internalize the cues or precepts of the socialization process wholly but rather accepts or rejects them. An individual will accept information from those who share similar views and shared beliefs, especially when such associations and beliefs are among people who share related commonalities or when these relationships support those behaviors in with which they desire to engage or interact (Simons- Morton Haynie \& Noelcke, 2009). The socialization and selection processes help to generate social norms. Social norms vary among social networks, each governed by a set of rules which pertain to behavior, customs and expectations. Social norms help the individual navigate through the complexity of these networks which are subject to change over time, thus one must integrate the values of the network through selection. (Simons- Morton Haynie \& Noelcke, 2009). Social network theory asserts that appropriate health-related behaviors are communicated to aging gay/bisexual Hispanic 
men in direct relation to their social networks (Berkman, 2002; Berkman \& Glass, 2002). In terms of overall health and the unique challenges facing aging gay/bisexual Hispanic men this knowledge can improve the understanding of the ways in which social networks can impact these individuals in terms of health behaviors and social support.

\section{Social Networks and Individual Level Considerations}

Clearly, individuals' experiences, use, access and perceptions of social networks are shaped by various forces. Identity level factors, such as race/ethnicity, sexual orientation, and gender, are particularly powerful, as research has shown in that they each affect individuals in unique ways. Thus, it is important to identify how the integration of these identities influence Hispanic gay men's views their social networks as it is related to their aging health experiences, given the correlation between health outcomes and social relationships (Chang, Wray, \& Lin, 2014).

Gender Considerations. According to research, men on average, do not live as long as women and this is seen across cultures (Miller, 2014). According to Miller, (2014) the average life expectancy of women is 81 years, and for men the average is 79 years. Older men are less likely to seek medical attention or take preventative health measures compared to women (Bertakis, 2000; Hankivsky, 2012). As a result men often have untreated conditions which have been left to worsen or become untreatable. Also, men are more likely to suffer heart disease, liver disorders, and other life threatening conditions as well as mental disorders (Brown, 2013; Collins, 2008; Kim, 2005; Vega, 2011). Suicide rates and alcohol abuse are significantly higher among aging men when compared to women and men tend to use more violent and effective methods like firearms when they attempt suicide (Callanan, 2012; Monnin, 2012). To better understand 
the health care concerns, it is necessary to consider the issue of gender differences in terms of how men and women access health care, the cultural and the social barriers involved in this process (Bertakis, 2000; Hankivsky, 2012).

Moreover, men are often not usually caregivers, even for themselves; the role is traditionally one for women (Denby, 2014; Geiger, 2015). Men often face special challenges in this regard and experience higher levels of stress than women in this role, partly the result of societal and cultural norms surrounding male stoicism and masculinity (Connel, 1995; Pascoe, 2007). Men experience comparatively increased social pressure than women and girls to endorse gendered societal prescriptions such as the strongly endorsed health-related beliefs that men are independent, self-reliant, strong, robust and tough (e.g., Courtenay, 2000). Similarly, they will not seek out supportive social networks to assist with or provide information that could help with their aging transitions. Gendered societal prescriptions in relation to gender role socialization can lead to compromised health outcomes, as research notes that men avoid putting time and energy into seeking health services because it is not a "male priority" (Courtenay, 2000; Kellogg, 2003; MacNaughton, 2008).

An increased understanding of gendered aging experiences provides insights into the special health needs and challenges of this growing population, particularly as it relates to discrimination, limited agency and diminished access to resources and isolation and loss of social support as a consequence of lost social networks (Fenkl, 2014; Knochel et al., 2010; Nemmers, 2004). 
Race/Ethnicity Considerations. The role of social networks within racial/ethnic communities is also important to consider because according to the CDC (2014), racial/ethnic experiences have a profound effect on health disparities outcomes. Minority groups do not have the same life expectancy as White non-Hispanics and they are also likely to have less access to health care and education on prevention as compared with White non-Hispanics (Brown, 2013; Collins, 2008, Kim et al., 2005; Vega, 2011). The experiences of minorities in the U.S. are often highlighted by discrimination, bigotry, diminished access to resources and lower social status compared with Whites (Brown, 2013; Purdie-Vaughns \& Eibach, 2008; Sidanius \& Pratto, 1999). The problem is exacerbated as many minority groups grow older. It is a form of intersectional marginalization, that is multiple levels of discrimination and ageism combined (PurdieVaughns \& Eibach, 2008; North \& Fiske, 2012; Stone \& McMinn, 2012). The net effect is that minority elderly groups face even worse realities than their White counterparts (Kornblum \& Julian, 2012). Despite these experiences, research consistently shows that having a strong, supportive and active social network decreases the impact and can contribute to increased psychological well- being among this population (Marquez et al. 2014).

When specifically considering the Hispanic population, census data notes that they will be the largest minority group in the U.S. by 2050 . The dramatic increase of population presents an even greater challenge because cultural filters that may mediate access to health care and other unique elements and cultural norms that should be taken into consideration to better serve the group (Census, 2013). In fact, researchers have already begun to identify culturally specific values and behaviors that buffer many 
Hispanics from age-related social and psychological well-being concerns. For example, although this population experiences high rates of negative health outcomes, the cultural value of familism, that is to say strong connections, allegiance and identification with one's family of origin is an important factor for many among the Hispanic culture (Sabogal et al. 1987). The core characteristic in the Hispanic culture has been identified as a primary socialization framework (Sabogal et al. 1987). It is characterized by the valuing of connectiveness (sense of belonging) among all family members, and emphasizes the centrality of the family unit (Sabogal et al. 1987). Hispanic familial culture stresses the importance of obligation of family members to provide support to fellow family members (Sabogal et al. 1987). The obligation and allegiance to family among Hispanic people extends to one's immediate family and extended kin and these social networks have been identified as powerful sources of support which can increase self-esteem, physical health, mental health and increased longevity among aging Hispanics (Albeda et al., 2009; Almaguer, 1991; Guzman, 2005; Kurtz, 1999; Mayer et al, 2009; Sabogal et al. 1987). Having family members physically present in one's life and committed to an individual's well-being ensures that they can better negotiate and keep track of health care concerns (Eschbach et al., 2004; Markides, Angel, Peek, 2013; Marquez et al., 2014).

Sexual Orientation Considerations. Another identity level factor that needs to be considered when examining aging populations and social networks is sexual orientation. In his study of aging and gay men Fenkl (2014) employed the definition of sexual orientation as, "As a constellation of affective, cognitive and behavioral characteristics that constitute an individual's sense of self as a sexual and intimately rational being" 
(Fassigner \& Arseneau, 2007). For those who identify as gay, this typically means the self-identification of one's sexual desire toward members of the same sex through early development into adulthood (Cass, 1984), yet others discuss gay identity as a complex interaction among multiple social meanings beyond behavior within a context of changing cues and sanctions within the social environment (Cross, \& Epting, 2005). These social cues are then processed and internalized in varying degrees contingent on multiple factors including race/ethnicity, social class, cultural and structural factors (Crawford et al., 2002). Another definition of the gay identity is discussed in the literature as individuals who do not fit exclusively into the binary gender schema, who often encounter negative sanctions against the backdrop of heteronomrative expectations (Fenkl, 2014). For the current study the term gay and gay identity is used as an umbrella term to refer to individuals who do not conform to heteronomrative binary gender expectation, which would include LGBT people.

Members of the LGBT community may face unique issues when it comes to familial support. Typically, close family, especially children, serve as key social supports for aging individuals (Adams \& Blieszner, 1995; Antonucci, 2001; Baltes, 1997, Boaz, 1999; Frazier \& Waid, 1999). Those with a small number of familial networks may face increased financial hardships, anxiety, isolation and depression that may have negative effects on overall health and quality of life (Adams \& Blieszner, 1995; Antonucci, 2001; Baltes, 1997, Boaz, 1999; Fenkl, 2014; Frazier \& Waid, 1999). The limited number of close supportive familial connections is concerning as some gay males lose familial support with disclosure of their sexual 
identity. More common is that many gay males do not have children, who would be able to serve as social supports or health advocates as they age (Patterson, 2000).

Despite recent changes in policy and attitudes about the LGBT community in the U.S., homophobia is persistent and remains a problem in many organizations that will directly serve the aging gay Hispanic population. For example, research studies have noted that in medical settings heteronormativity frames much of the language and interactions with clients (Clover, 2006; Fenkl, 2014; Hinchliff \& Gott, 2011; Knochel et al., 2010). For example, research has noted that health care providers often make assumptions about life-style choices and morality that do not reflect the experiences of non-heterosexual populations (Ahmad \& Bhugra, 2010; Dworkin \& Yi, 2003; Fenkl, 2014). Similarly, studies have noted that health care providers, doctors, nurses and assisted living facilities often treat aging gay persons with hostility and disgust because they lack awareness about non-heterosexual lifestyles (Dovidio \& Gaertner, 2010; Johnson et al, 2005; Knochel et al., 2010; Nemmers, 2004).

\section{Social Networks and Aging Hispanic Gay Men}

Researchers working on aging have shed light on the importance of successful aging and social support (Adams \& Blieszner, 1995; Antonucci, 2001; Baltes, 1997, Frazier \& Waid, 1999). Aging and loss of function is inevitable, however, the impact of strong social support has been shown to have positive influences on aging well (Adams \& Blieszner, 1995; Antonucci, 2001; Baltes, 1997, Frazier \& Waid, 1999). Key variables on successful aging include the interrelated elements of support, both instrumental support and emotional support (Adams \& Blieszner, 1995; Antonucci, 2001; Baltes, 1997, Frazier 
\& Waid, 1999). Moreover, the aging population and quality of life often reflects the social and functional aspects of daily living.

As previously discussed, Hispanic gay men's access to social networks are often limited (Albeda et al., 2009; Almaguer, 1991; Guzman, 2005; Kurtz, 1999; Mayer et al, 2009). Of the limited resources that exist for gay and bisexual individuals, few specifically target the needs of older adults (NHCOA, 2013). Care options often include heteronormative spaces, homophobic doctors, nurses, and staff (Ahmad \& Bhugra, 2010; Hinchliff, 2005, Mayer et al., 2009). Elderly LGBT people have reported abuse and discrimination as doctors and caregivers may have no training or understanding of their unique challenges and limitations (Dovidio, 2010, Fenkl, 2014; Guzman, 2005; Knochel et al., 2010; Myall et al, 2009). The HIV/AIDS epidemic of the 1980s forced the U.S. government and many social institutions and the medical community to recognize that homophobic attitudes and denial could no longer be the routine given the magnitude of the infection on society as a whole (Ahmad \& Bhugra, 2010; Dworkin \& Yi, 2003; Jay, 2000; Johnson, 1992; Mayer et al., 2008; Rupp, 1999). Instead, doctors began to recognize the need for a better understanding; one which addressed the unique challenges facing the LGBT community (Ahmad \& Bhugra, 2010; Mayer et al., 2008). Oppression is often embedded into many social institutions which have direct consequences for minority groups including health disparities (Almaguer, 1991, Kurtz, 1999; Moraga, 1993; Sebesta and Vollmer, 2007; Thompson, 2015).

Older Hispanic gay men may also face the potential rejection and ostracism of their families who may be their only form of support yet may inflict the greatest degree of homophobia and intolerance (Kurtz, 1999; Sebesta \& Vollmer, 2007). Racial/ethnic 
minorities often rely on family as a buttress against oppression out of necessity (Almaguer, 1991; Guerrero, 2013; Guzman, 2005; Kurtz, 1999; Moraga, 1993; Peralta et al., 2013; Vega, 2011). The support of close family has been found to be vital in healthy aging (Baltes, 1998; Boaz, 1999). However, Hispanic gay men face a difficult challenge, of the possible loss of family support if they reveal their identity as gay thus putting them at risk of losing a major source of social and emotional (Almaguer, 1991; Guerrero, 2013; Guzman, 2005; Kurtz, 1999; Moraga, 1993; Peralta et al., 2013; Vega, 2011). The combination of these negative experiences often lead racial/ethnic sexual minorities to live compartmentalized, double-lives as a means to ensure that various social supports remain in their lives (Almaguer, 1991; Guerrero, 2013; Guzman, 2005; Kurtz, 1999; Moraga, 1993; Peralta et al., 2013; Vega, 2011). The silencing of lifestyle realities, however, can have negative physiological results, and increases risk of negative physical health and mental health outcomes and substance abuse (Briane et al., 2011; Crawford, et al., 2002; Dworkin \& Yi, 2005; Fergus \& Darbes, 2009; Friedman et al., 2008; Green, 2008; Herek \& Garnets, 2007; Purdie-Vaughns \& Eibach, 2008). Racial/ethnic sexual minorities must often reconcile impossible alternatives and limited support or make choices on the basis of fear of losing what meager resources which are available to them (Almaguer, 1991; Darbes \& Lewis, 2005; Green, 2008; Kurtz, 1999). Green (2008) found that ethnic-minority gay men have lower sexual status among the mostly White business locations and other organizations that cater to the mainstream gay community (Almaguer, 1991; Darbes \& Lewis, 2005; Green, 2008; Kurtz, 1999). The perception of discrimination among ethnic minorities translates into decreased access to social networks and social cohesion for racial/ethnic-minority members among the larger White 
gay community. The perceived rejection and out-group status experienced by ethnic minorities can contribute to lower esteem, greater isolation, and negative impact on physical and psychological well-being (Ahmad \& Bhugra, 2010; Green, 2008; Guzman, 2005; Kurtz, 1999).

Studies have also shown that men with low sexual status (e.g., sexual and racial/ethnic minorities) face significant stressors have also been found to face limited, personal support resources, including self-esteem, sense of social support, and sense of control (Ahmad \& Bhugra, 2010; Green, 2008; Kurtz, 1999). Green (2008) found that some low status gay/bisexual men were unable to consistently negotiate condom use as a consequence of a history of field stressors and diminished personal resources. Since racial/ethnic minorities within the larger gay community context face an added degree of stigma and isolation (Ahmad \& Bhugra, 2010; Green, 2008; Guzman, 2005; Kurtz, 1999) the need to secure and establish social networks, a sense of community and solidarity are critical in terms of overall health, especially since there has been a steady decline in gaypositive spaces throughout the United States (Sebesta \& Vollmer, 2007; Wilkin \& BallRokeach, 2006).

\section{The Current Study}

Several studies have noted the importance of social networks as it relates to aging, health and health disparity outcomes (Chang, Wray, \& Lin, 2014; Sneed \& Cohen, 2014; Wu, 2004). While these studies provide important insights, they primarily focus on White or heterosexual samples. Similarly, Hispanic community-focused samples do not capture sexual minority experiences, thus failing to capture a full picture of this diverse population. According to Gates (2013) over one million Hispanics identify as gay and 
lesbian in the U.S. It is problematic that few have drawn exclusively from Hispanic gay male populations given census data predicts the increasing number of men in late adulthood identifying as gay or bisexual which is on the rise relative to the growing number of aging minorities in general (Clover, 2006; Fenkl, 2014; Gates, 2013; Grant, 2006; Williams \& Mohammed, 2009). The shift in the aging populations' diversity challenge researchers to increase knowledge about their health needs, and related social network processes.

The current study would build upon existing aging health research by exploring a significant subgroup of the late adulthood population- Hispanic gay men who are between the ages of 50 to 70 . Specifically, the present study identifies social network structures, functions, and quality, to understand their association with well-being around aging concerns of the focal population. The current study identifies these social networks of which older Hispanic gay men perceive as having an influence on their health and aging experiences, and explores how do social networks help and/or hinder older Hispanic gay in terms of their health perceptions and experiences. The findings from this work will help researchers better understand this understudied populations' unique needs and challenges, particularly as it applies to access to health, public policy and preparedness, all concerns identified as lacking in the current literature (Ahmad \& Bhugra, 2010; Almaguer, 1997; Fenkl, 2014; Green, 2005; Kurtz, 1999; Purdie-Vaughns \& Eibach, 2008; Williams \& Mohammed, 2009).

To guide the current study, two overarching research questions have been identified:

1: What social networks do older Hispanic gay/bisexual men perceive 
as having an influence on their health and aging experiences?

2: How do these social networks help and/ or hinder older Hispanic gay men's ability to address these factors influencing their health and aging experiences? 


\section{METHODS}

The objective of the current study was to identify the social networks that self-identified Hispanic gay/bisexual men utilized to negotiate their aging related health concerns. In order to contribute to the limited body of research focused on aging Hispanic gay men; the current study utilized qualitative methods as an approach to establishing foundational information specific to their experiences. This chapter provides a review of why a qualitative approach was employed and discusses the guiding framework and discusses selected aspects of the study design. Issues of validity and reliability are also addressed in this section. Finally, the methodologies for data collection and analysis are outlined in detail.

\section{Qualitative Methodology}

The majority of research examining aging gay/bisexual Hispanic men's experiences and realities are often extrapolated from research on aging or aging of LGBT White non-Hispanic populations (Clover, 2006; Johnson et al, 2005; Knochel et al., 2010; Fenkl, 2014). Missing from this research are the realities for the double-minority; identifying as LGBT and as an ethnic-minority (Kurtz, 1999; Crawford, et al, 2002; Jost, Banaji, \& Nosek., 2004). Given limited research in the area, the present study employs qualitative designs to understand the unique experiences and challenges for aging gay/bisexual Hispanic men between the ages of 50 to 70 through the identification of their social networks.

In his study examining the experiences of aging gay men, Fenkl (2014) argues that quantitative research; while quite useful in providing reliable information on large populations can miss the subtle details about the lived experiences of unique populations, 
like ethnic-minority gay men. Self-identified aging gay/bisexual Hispanic men differ from Whites or other racial/ethnic groups in their experiences, and using qualitative methods is ideal in capturing information about ethnic-minority gay men (Few, Stephens, $\&$ Rouse-Arnette, 2003). Qualitative methods are quite distinct from quantitative methods which rely on the statistical analysis of variables and manipulation of variables while employing statistical methodology and this can be misleading depending on which variables are being controlled during the analysis process (Babbie, 2005). Further, given its reliance on the interpretation of statistical data, quantitative data cannot describe specific subjective unique experiences and detailed perceptions about aging gay/bisexual Hispanic individuals (Few, Stephens \& Rouse-Arnette, 2003).

To address the void in the research on aging gay Hispanic men, qualitative research has been used in the current study to facilitate access to the focal population and increase understandings of the meanings and experiences aging Hispanic gay men give to social networks they utilize (Babbie, 2005; Berg, 2006; Laverty, 2003). Through indepth interviews, for example, researchers can better gather data on their personal experiences, perceptions and personal narratives surrounding health concerns like social connections, access to resources and identity development and the negotiation of identities (Clover, 2006; Johnson et al, 2005; Knochel et al., 2010; Fenkl, 2014). Their own perspectives and personal narratives facilitated through qualitative analysis provides rich descriptions and increased understanding which has many implications toward improving the quality of care and overall health outcomes for the focal population (Geertz, 1973; Maxwell, 1996; Laverty, 2003). 
Qualitative research also focuses on exploring social environs and the description of those living and negotiating social contexts, and thus can provide keen insights and definitions to their shared experiences within a social context through the analysis of transcriptions of detailed in-depth interviews (Maxwell, 1996; Strauss \& Corbin, 1990). Qualitative research is guided by inductive logic in that the field (research site) and the subjects provide information, clues and myriad data about their lived experiences, which can provide increased understanding of the phenomena being studied (Strauss \& Corbin, 1990). Embedded within qualitative research is the paradigm of phenomenology (Laverty, 2003), which asserts that individuals shape and participate in the construction of reality and its norms; and are consequently subject to these norms and sanctions. These social interactions produce experiences and challenges for the individual and are thus significant elements to be studied. Examining these phenomena is vital in gaining a rich and comprehensive understanding of the target group (Maxwell, 1996; Strauss \& Corbin, 1990). One of the foundations of qualitative research is to examine the process by which people come to understand their world and how they construct meaning in a social context and how these social forces impact their lives; as groups and individuals accessed through interviews and in some cases participatory observations (Babbie, 2005; Fenkl, 2014; Laverty, 2003; Strauss \& Corbin, 1990).

Interviews. Qualitative methods include the use of interviewing members of the target group (Babbie, 2005; Berg, 2006). Interviewing subjects facilitates access to personal narratives, which is helpful in obtaining insights and thick descriptions of experiences and perceptions (Geertz, 1973). In-depth interviews gather accurate and comprehensive data on often elusive or inaccessible subcultures from the focal 
population itself (Babbie, 2005; Fenkl, 2014). Moreover, the use of qualitative methods, particularly interviews or narrative documents, has been extremely effective for gathering accurate and comprehensive information from "hard to reach" populations. Specifically, qualitative methodologies have been instrumental in informing researchers of the various dynamics, lived experiences, cultural challenges and social interactions that shape one's sexuality, identity in terms of race/ethnicity, and gender norms through in-depth interviews and in some cases participatory observation (Few, Stephens, \& Rouse-Arnette, 2003). Few, Stephens, and Rouse-Arnette (2003) argue that interviewing provides the most effective method for validating and centering experiences of members of a marginalized group, in particular for the present study, aging gay/bisexual Hispanic men. Comprehensive, rich descriptions of the subject's interpretations of the phenomenon being studied in specific contexts or social setting or social location are key characteristics of the interviewing process (Few, Stephens, \& Rouse-Arnette, 2003; Geertz, 1973; Strauss \& Corbin, 1990).

\section{Content Analysis}

The present study specifically employed the content analysis approach to systematically describe social networks utilized by the understudied population through the examination of transcripts of interviews and through the examination of survey questions based on demographic data of the focal population. In the current study, its ability to guide the classification of open-ended interview responses and survey questions provides a quantitative (numerical) description along with qualitative findings that emerge from the data (Vaismoradi, Turunen, \& Bondas, 2013). The use of this qualitative descriptive method is suitable for a content analysis study as it aims to interpret foundation 
information about a specific phenomenon experienced by the focal population (Vaismoradi, Turunen, \& Bondas, 2013). Specifically, content analysis is most useful when conducting exploratory work on a topic where there has been little research and knowledge generated (Vaismoradi, Turunen, \& Bondas, 2013). It provides foundational information about the common and core themes within the data, which can then be used in future research to develop more complex questions for interviews or surveys (Green \& Thorogood, 2004).

Content analysis provides descriptions of the characteristics of an interview's content by examining who say what, about whom, and with what effect on an individuals' identity, behavior, lived experiences and perceptions (Bloor \& Wood, 2006). The systematic coding and categorizing approach achieves access to these phenomena through the exploration of textual information, and then identifying trends and patterns of words used, their occurrences, their connectedness, and the organization and content of communications (Gbrich, 2007; Vaismoradi, Turunen, \& Bondas, 2013). Thus, the content analysis approach is suitable for answering broad level questions that ask: what are the concerns of people about an event? What reasons do people have for using or not using a service or procedure? (Vaismoradi, Turunen, \& Bondas, 2013).

The data are analyzed through the process of open coding and creating categories based on emergent themes in the transcripts. The coding process then leads to the grouping of codes under higher order headings, and the formulation of a general description of the research topic through generating categories and subcategories as abstracting. 
In the context of the current study, it is clear that content analysis is well-suited to analyze the previous unexplored, subjective and personal nature of the questions being asked about aging, health and social networks.

\section{Evidence of Quality}

In qualitative research it is necessary to ensure rigor so that findings can be trusted and that credibility is established no matter what methodology is used (Lincoln \& Guba, 1985). The concept is known in qualitative research as trustworthiness (Fenkl, 2014; Gbrich, 2007; Green \& Thorogood, 2004). The requirements for ensuring trustworthiness are critical in qualitative studies and mirror the concerns in quantitative studies in terms of validity and reliability (Babbie, 2005; Gbrich, 2007). The criteria for trustworthiness in research, particularly quantitative methodologies, are internal validity, external validity, and reliability (Babbie, 2005; Green \& Thorogood, 2004). However, qualitative research and its aims differ from quantitative approaches in the way it establishes credibility and rigor in its methods and data collection (Gbrich, 2007). To better highlight the differences between quantitative and qualitative methods, Lincoln and Guba (1981) further discuss these concepts as three components of a trustworthiness model: "credibility" for internal validity, "transferability" for external validity, and “dependability” for reliability (Few, Stephens, \& Rouse, 2003; Gbrich, 2007; Strauss \& Corbin, 1990).

Credibility. The concept of credibility involves ensuring that the research accurately represents the lived experiences, perceptions, behaviors and self-concept of the participants of the study through in-depth interviews and through the examination of 
survey question responses of the focal population (Fenkl, 2014; Few, Stephens, \& Rouse, 2003; Gbrich, 2007; Green \& Thorogood, 2004; Strauss \& Corbin, 1990).

Credibility is identified by Lincoln and Guba (1985) as an important goal of qualitative research and is comparable to the concept of internal validity in quantitative research. According to Fenkl (2014), "Credibility refers to confidence in the truth of the data and the interpretation of that data". This is achieved through rigorous ongoing procedures which guide the study. Specifically, this is accomplished through prolonged engagement, persistent observation, peer debriefing and negative case analysis (Fenkl, 2014; Few, Stephens, \& Rouse, 2003).

The process of prolonged engagement as discussed by Lincoln and Guba (1985) involves the investment of time with focal population during the process of data collection which can provide an increased understanding of the lived experiences and perceptions of the focal population. According to Lincoln and Guba (1985) prolonged engagement provides scope or range of the phenomenon being studied. During prolonged engagement of the focal population trust was built with the research which facilitated honest responses of the subjects in the study. The subject's level of trust of the researcher is critical in terms of access to their candor about lived experiences and perceptions related to aging and minority status (Charmaz, 2006; Fenkl, 2014; Few, Stephens, \& Rouse, 2003). The employment of prolonged engagement helps to ensure credibility to other researchers interested in the focal population (Fenk, 2014).

According to Lincoln and Guba (1985) while prolonged engagement provides a range or the scope of the phenomena being studied, persistent observation provides depth of these phenomena by focusing questions and returning to the questions and recurrent 
themes based on commentary of the subject or their lived experiences. In the case of the current study the persistent observation focused on the lived experiences and perceptions of the focal population related to aging and minority status. The goal of achieving persistent observation was facilitated through in-depth interviewing and open-ended questions. The subjects were given adequate time to reflect on the questions for as long as each wished, allowing increased freedom of expression and candid detailed responses. Moreover, the researcher would return to previously asked questions and allowed the subject to elaborate in relation to other elements which emerged during the interview related to aging and minority status. The time of each interview ranged from 30 minutes to one hour based on the subject's comfort level and willingness to continue participation of the interview. The method of persistent observation was employed to explore the minute details of the lived experiences of the subject related to aging and minority status. The research would ask the subject if they would like to expand on his response after each question and when the subject was vague in his response. In addition the use of notes on the subject's body language and tone were taken during each interview to help address concerns of persistent observation as discussed by Fenkl (2014).

The next method to ensure credibility that was employed in the current study was facilitated through peer debriefing with the researcher's major professor who served as an expert in qualitative methodology. Peer debriefing is a necessary component of qualitative methodology in order to ensure credibility by allowing the researcher to gain increased objectivity through the aid of an expert through challenging the researcher's assumptions about the data and to allow the research the ability to share ideas and expose potential biases. Peer debriefing sessions occurred on a bi-weekly basis where the 
researcher's major professor asked probing questions about the researcher's assumptions and possible biases throughout the data collection process. Moreover the researcher's major professor discussed the qualitative methodology based on expert theorist in qualitative analysis. The researcher's major professor engaged the researcher with challenging questions and through the discussion of alternative hypotheses, and perceptions of the researcher on the data being collected and analyzed.

In addition to the above mentioned strategies to ensure credibility, the method of the negative case was employed. According to Lincoln and Guba (1985) negative case analysis involves actively seeking identifying elements of the data which challenge the emergent patterns or which run counter to the portions of the collected data or its analysis. The analyses of the negative case or cases that emerge from the data help provide the researcher with increased description of the data being collected and analyzed. The descriptions of subjects that contradict or that are incongruent with the descriptions of other subjects helps to ensure credibility by providing more details on the variety of lived experiences and perceptions of aging gay Hispanic men. In keeping with the strategy of using the negative case, the researcher sought out contradictory evidence among subjects through purposive sampling until saturation was achieved, that is no novel information was to be generated by further sampling. The current study engaged purposive sampling in order to recruit a diverse sample of aging gay Hispanic men from different age groups, between 50 and 70 years of age, from diverse ethnic backgrounds (i.e., American-Hispanic, Colombian, Cuban, Mexican, Puerto Rican, and Venezuelan), from diverse socioeconomic levels and from different education levels in the pursuit of the negative case as discussed by Lincoln and Guba (1985) in order to ensure credibility 
and to capture comprehensive description of the experiences of aging among gay Hispanic men living in South Florida. The present study employed strategies discussed above to confirm that proper procedures of data collection and analysis were achieved (Fenkl, 2014; Few, Stephens, \& Rouse, 2003; Gbrich, 2007; Lincoln \& Guba, 1995).

Transferability. The degree to which another researcher is able to reconstruct a study in which there are similar contexts and populations being examined is known as transferability (Lincoln \& Guba, 1995). Transferability can be compared with the concept of generalizability in quantitative research. However, it is important to note that in qualitative research, the goal is not to generalize or compare the results beyond the participants of the study (Fenkl, 2014; Few, Stephens, \& Rouse, 2003; Strauss \& Corbin, 1990). Unlike quantitative research which provides statistical measures and their potential for generalizability, a qualitative study, rich with descriptions of phenomena, can provide the necessary information for others interested in applying the findings with careful consideration through the examination of transcripts and though the comparison of demographic data of the focal population (Fenkl, 2014; Few, Stephens, \& Rouse, 2003; Strauss \& Corbin, 1990). According to researchers in qualitative methods (Fenkl, 2014; Few, Stephens, \& Rouse, 2003; Lincoln \& Guba, 1985; Strauss \& Corbin, 1990) the responsibility of the researcher employing qualitative methods is to provide adequate description of the phenomena being studied so that other researchers can evaluate the data and if it is applicable their own study. According to Lincoln and Guba (1985) transferability can be facilitated through extensive description of the data being collected known as "thick" description. In turn, these thick descriptions provide adequate details for other researchers who can determine if the conclusions of one qualitative study are 
transferable to other focal populations or not. The current study employed the strategy of using thick description to this end through in-depth interviews, demographic data of the focal population and through purposive sampling where a diverse range of ethnicity, age, socioeconomic levels and levels of education of subjects were recruited in order to include comprehensive description of the focal population.

Methodologists Lincoln and Guba (1985) asserted that social dynamics are constantly in a state of flux and there is no expectation for a qualitative phenomenological study to predict the likelihood of similar findings in subsequent examination. Rather, drawing from extant qualitative grounded research may or may not generate similar findings and may lead to further understanding of the phenomena being studied (Fenkl, 2014; Few, Stephens, \& Rouse, 2003; Strauss \& Corbin, 1990).

Dependability. In qualitative research the issue of reliability (the extent to which one's findings can be found again) is complex and assessed through dependability (Strauss \& Corbin, 1990). As reliability is dependent on the ability to produce the same results in another study, there is an assumption of quantitative methods that there is one unchanging reality; an assertion that does not fit with the frameworks of qualitative research. Recognizing the limitations of quantitative research methods, qualitative research instead focuses on issues of consistency in the findings generated by the focal population through in-depth interviews, the examination of survey question responses and the researcher's field notes. The information generated by the focal population through in-depth interviews, responses to survey questions and the researcher's filed notes are important since the data are based on the lived experiences of the focal population. The goal of qualitative methods is to ensure the results of the study are 
consistent with data collection processes findings and influences based on the focal population's unique experiences and lived realities (Fenk, 2014; Few, Stephens, \& Rouse, 2003; Green \& Thorogood, 2004).

There are specific ways in which dependability, through assessments of consistency, is achieved. To address these concerns, the current study provides a dense description of research methods, conducting dependability audits and triangulating multiple sources. The audit (i.e., data collection methods, decision making processes, and categorization) involved providing detailed methodological information to ensure other researchers have an outline to replicate the study or derive comparable results in future work (Green \& Thorogood, 2004). Recognizing the interpretative nature of the data collection and data analysis in qualitative methodologies, triangulation was used as a means in addressing concerns about validity (Babbie, 2005; Green \& Thorogood, 2004). Triangulation refers to the use of multiple sources of data and/or multiple methods to confirm emergent findings (Babbie, 2005; Green \& Thorogood, 2004). These foundational approaches work to ensure that the current study meets the criteria for ethical and robust analysis (Green \& Thorogood, 2004; Lincoln \& Guba, 1985). In the current study, basic demographic data, responses to survey questions, interview transcripts and researcher notes were utilized which are commonly used methods in qualitative research (Babbie, 2005; Fenkl, 2014; Few, Stephens, \& Rouse, 2003; Green \& Thorogood, 2004). Details of how this research process took place are discussed in the following section. 


\section{Researcher Subjectivity}

Qualitative research requires that researchers recognize the potential for bias in terms of data collection and the interpretation of data. Researchers must employ rigorous methods to mitigate the potential for bias throughout the study (Collins, 1998; Lincoln \& Guba, 1985). Throughout the research process of the current study a concerted effort was made by the researcher to be consciously aware of the potential for bias during the collection, coding and analysis in the research process (Lincoln \& Guba, 1985). The process of peer debriefing and review of data collection methods, as discussed by Lincoln and Guba (1985), was employed in the current study to maintain objectivity with the researcher's major professor. In-depth engaging debriefing sessions were held bi-weekly throughout the study with the researcher's major professor which helped in maintaining objectivity in reviewing the interview data. The process of peer debriefing sessions with the researcher's major professor included probing questions about data collection and the researcher's perceptions and experiences during the interviews to help mitigate any potential for bias on the part of the researcher. This process was critical in maintaining objectivity by examining and explanations of the observed phenomena during data collection, coding and analysis of the data (Vaismoradi, Turunen, \& Bondas, 2013).

\section{Approach}

Sampling. The current study used purposeful sampling, which involved identifying participants who might give the most comprehensive and knowledgeable information on aging gay/bisexual Hispanic men. Purposive sampling was used to gain a deeper understanding of the target population where information rich cases would 
provide invaluable insights which are of central importance to the purpose of the research (Few, Stephens, \& Rouse, 2003; Strauss \& Corbin, 1990).

Employing a grounded theoretical approach requires that individuals who have shared experiences and similar challenges negotiating multiple marginalized identities were recruited for the current study (Few, Stephens, \& Rouse, 2003; Strauss \& Corbin, 1990).

Participants. The participants of the current study included 20 self-identifying gay/bisexual Hispanic men between 50 and 70 years of age. The use of purposive sampling as discussed by Lincoln and Guba (1985) does not specify sample size but rather is emergent and continues until saturation in data is reached. Unlike randomsampling methods used in quantitative methods (Babbie, 2005), purposive sampling does not specify sample size (Lincoln \& Guba, 1985). Snowball sampling is another element which will likely identify other members of the population who may be potential candidates of the study. Snowball sampling was used in the recruitment of potential subjects through referral of others within the community. Further, snowball sampling can provide access hard to reach populations (Babbie, 2005; Few, Stephens, \& Rouse, 2003; Strauss \& Corbin, 1990). Participants may feel more comfortable learning about the study through friends and close associates within the target group. Fenkl (2014) discusses the challenges of reaching and gaining trust among intersectional minority groups which makes snowball sampling a valued method for recruitment.

Recruitment. Twenty gay/bisexual Hispanic men between the ages 50 to 70 were recruited to participate in the study. Institutional Review Board (IRB) approval was obtained prior to research and consent forms were administered and collected from those 
subjects who agreed to be in the study prior to interviews and basic demographic survey. Only those who gave their consent and identified as gay/bisexual, Hispanic and between the ages of 50 to 70 were permitted to become part of the study.

Confidentiality was maintained by not including any identifying information during the collection and write-up of data but rather nicknames were chosen by the participant at the time consent is obtained. Audiotapes, consent forms, researcher journal entries, transcripts, and computer files will not contain the names of the participants. All interviews were audio taped by the PI. For participating in the focus group, the participants were provided with a $\$ 10.00$ gift card at the end of the study. The money for the gift cards were paid for by the graduate student author from personal funds.

Data Collection. Three data collection techniques were used: 1) semi-structured interviews, 2) basic demographic questionnaire, and 3) researcher notes. These multiple sources of data, discussed in the following sections, were collected in order to triangulate the data and to confirm emergent themes and inconsistencies in the data.

A questioning route used by Fenkl (2014) was modified and employed in the study to capture the social networks utilized by self-identified aging gay/bisexual Hispanic men. The questioning route provided a framework for developing and sequencing a series of focused, yet flexible questions (Rubin \& Rubin, 1995). Probes were used so that each question may elicit further information regarding the realities and lives experiences of self-identified aging gay/bisexual Hispanic men.

During each interview, notes of participants' body language, questions that drew long pauses or silences from the participant, communication styles and dynamics, and 
issues that emerged as salient to the participants were recorded through note taking by the researcher.

Researcher's Notes. The researcher took detailed notes about the participantresearcher interactions and salient features that emerged through the interview (Few, Stephens, \& Rouse- Arnette, 2003). Interactions between participant and researcher including, body language, question probes, and outlines of possible categories, themes, and patterns were also included in the researcher's notes (Babbie, 2005; Berg, 2006; Laverty, 2003; Maxwell, 1996). Fenkl (2014) discusses the importance of taking elaborate notes in the event of recording equipment error or loss of audio recording of interview so that rich details could be included in the analysis.

It is important at this point to highlight and acknowledge the dynamics of the interactions between the participants and researcher interactions in the current study (Lincoln \& Guba, 1985). Beliefs and values given to racial/ethnic identity, orientation class, gender, nationality, age and power were examined in the interview process. As discussed by Fenkl (2014) access to the target group, given the potential threat of identifying as a marginalized group member, the researcher had to gain trust over time through engagement with participants and through snowball sampling in order to access this group (Few, Stephens, \& Rouse, 2003; Strauss \& Corbin, 1990).

Data Analysis. Content analysis coding involves the reviewing of transcripts, transcribed or synthesized, and the dissection of these data into them meaningful categories (Vaismoradi, Turunen, \& Bondas, 2013). Coding is a process that serves to categorize and describe the data (Bloor \& Wood, 2006; Vaismoradi, Turunen, \& Bondas, 2013). Initially one does open coding, which means considering the data in minute detail 
while developing some initial categories. Later, one moves to more selective coding, which involves systematically coding transcript statements with respect to a core concept- in the case of the current study around aging issues and minority status experienced by the focal population.

The process of analysis utilized open coding which is the process of developing of categories of themes and concepts that emerged from the collection of data (Bloor \& Wood, 2006). Governed by inductive reasoning an exploration of the data takes place without making any assumptions a priori of what might be discovered. The interviews were transcribed by three undergraduate research assistants who were not included in any other stage of the data analysis process.

A detailed examination of their transcripts took place following a line-by-line process, key issues and themes discussed by participants and inherent contradictions were highlighted by the faculty advisor, graduate student author, and undergraduate research assistants. The data analysis process began with two additional undergraduate research assistants and graduate student author reviewing each transcript line-by-line and coded using open-coding techniques developed by the faculty advisor. Codes were compared to the previous codes as they were identified during subsequent reviews. Initial codes were then reviewed and organized into groups or themes in the second stage of analysis. Beginning with the first interview transcript to each subsequent interview transcript, codes and categories were compared between all interviews. This method of analysis connected developing categories with emerging relationships between categories. The approach to examining the data was used throughout the entire analysis process. 


\section{RESULTS}

\section{Overview}

In this chapter, the significant themes that became clear through data analysis are presented. The data from three sources (interview transcripts, demographic, and researcher notes) were integrated into this overview of two broad questions that served to guide the current study:

1: What social networks do older Hispanic gay/bisexual men perceive as having an influence on their health and aging experiences?

2: How do these social networks help and/ or hinder older Hispanic gay men's ability to address these factors influencing their health and aging experiences?

Several themes emerged from discussions with these older Hispanic gay men that focused on their experiences and perceptions of social networks influencing their experiences with aging. A total of three broad social network themes emerged from the data that included: 1) health and aging concerns, 2) current social networks, and 3) desired social networks. Within each of these, factors tied to identity level concerns emerged. Specifically, their gay, Hispanic, and socioeconomic status identities also emerged as key identity level factors. Each of these themes is discussed in the following sections. 


\section{Demographic Profiles}

The population emerged as being diverse in terms of countries of origin, length of time in the United Sates and levels of education (see Table 1). At the time of the interview most participants were still activity working $(n=15)$ which is consistent with state and national averages. According to the Florida Legislature Office of Economic and Demographic Research (2014) older workers ages 65 and older continue to working which represents an increase of $10.3 \%$ in 2000 to a high of 16.55 in 2010 . According to the U.S. Department of Labor (2008) working adults ages 65 and over has increased from 1977 to 2007 by 101 percent. Only five of the participants in retirement which is consistent with national averages on people with retirement plans. According to the National Institute on Retirement Security (2010) over 45 percent of working adults have no retirement plan. Over three quarters of the participants had some form of health insurance $(n=16)$, although only three had retirement plans.

In terms of social relationships, the majority were single $(n=14)$, and four of the six men with partners were cohabitating. The majority were childless $(n=19)$. When considering family and friends' knowledge of their sexual orientation, most participants were out to their mothers $(n=15)$ and siblings $(n=16)$. However, few were out to their fathers $(n=5)$ and their extended family members $(n=5)$.

\section{Aging-Related Health Concerns}

To identify what key aging related health concerns these men had, their response to the question "What are your concerns for the immediate future?" were analyzed. Although the question specifically focused on their current aging health concerns, all participants linked their response to its relationship to long term outcomes. In all, three 
broad themes emerged from this area of inquiry. The first most cited concerns were associated with finances $(n=16)$, followed by loneliness $(n=14)$, and negative health outcomes $(n=10)$.

Finances. Finances emerged as the most significant concern of these men related to their health as they aged $(n=19)$. Health care costs, ability to pay general bills, affording resources, lifestyle maintenance, perceptions of ability retire, and need to continue working were coded as financial concerns. There were seven men who specifically expressed concerns about their inability to afford health care and basic living costs as they aged. Understandably, when discussing these issues these men linked finances to their ability to maintain both their physical and psychological wellbeing.

It's very scary, um for me it's very scary because I have no idea what my old age will be like, so I don't know what, um, and I don't know if I will have the financial resources to be able to afford the care and support that I need as an aging gay man that has no children. And I don't know if my partner will be around or not, so um you know I'm kind of looking at myself as an aging gay man as being on my own and then will I have the resources necessary to help me out. (Alberto) I am a hard worker, I had, (stammers) to be honest, I work very hard. I have a very nice job. I really like it, but uh (pause) $85 \%$ of my salaries going to my rent, my cable, that I (stammers) said, I am going to repeat it, my basic things. 
So really only get $10 \%$ really, for food, and my food is very

mediocre. You know, I only have for the basic, maybe

chicken and milk, uh, (pause) because I live in Miami and

Miami became so expensive- the rent. (Eduardo)

The importance of financial security was raised by those men who reported themselves as financially secure $(n=4)$. They acknowledge that finances played a role in their ability to address aging concerns. As a result, their fears about aging were less pronounced among these three men because they felt they could have afford an enjoyable lifestyle and address costs associated with health concerns.

At this point, as I said before, I live one day at a time I don't really look in the future, I live in the present, ah, thank goodness, eh, financially we're ok, so we don't have to be worried about the future, so that's one of the reasons I live to the today, thinking whatever happen tomorrowhappen. (Dana)

Loneliness. Loneliness was also an important health concern that over two-thirds of these men associated with aging $(n=14)$. Coded as lack of contact with individuals or broader society, loneliness defined by these men as having no/ few friends or social groups, feeling isolated, desiring social connection, or lacking regular, meaningful relationships with groups or individuals. Of the men that identified this as a health related issue, eight specifically noted that it was increasingly significant. They expressed fear and regret about this occurring or progressively becoming a reality to them as they age. 
The only thing that I really, that really bugs me (pause) and I'll blame it on myself probably, I'm not a very social, you know sociable person. Not, you know, because I don't want to but it's because in some ways I might me a little afraid, of people trying to take advantage if you know, my age. And therefore you know I don't give myself a lot of open, you know I'm not completely open towards you know the [members of the gay community] out there. (Leonardo) Aging is very important that everybody be conscious about this- one cannot stay sexy or in love forever. But when we are conscious that it's not forever- conscious about what's going to happen with you with certain age you can... you can, you're not going to be able to take care of yourself- it is very important. Most of the gay people live by themselves, and then become concerned about [being alone] at this point. (Eduardo)

Well, I'm uh I think that aging is for everybody the same. I think it's not easy, um, probably for gay people, because loneliness is a factor that makes aging more difficult [as a gay man]. (Walter)

Partnerships, in terms of a spouse or long term boyfriend, was also key to avoiding loneliness. Both men in partnerships and those that were single acknowledged that this social network was important for avoiding loneliness $(n=9)$. Having someone to 
grow old with meant increased financial security, companionship, and the possibility of a caretaker if health issues became physically or psychologically debilitating, according to the men's responses.

I have a partner, so I feel kind of secure that I have someone there to, uh grow old with. I am lucky because not everyone has that- it could be scary. (Erik)

Ageism also emerged as an issue that contributed to loneliness, as it was perceived as a barrier to forming of intimate partnerships. Ageism is the act of discriminating or stereotyping individuals on the basis of age. Just over one third of the men in the current study felt that it was a unique issue within gay community, because of perceived cultural pressures to always appear young, beautiful and sexual $(n=7)$. Those that do not meet these criteria are viewed as undesirable and unable to secure both short term (e.g., sexual or "friends with benefits") or long term (e.g., committed, marriage) relationships.

Well, aging sucks because now my availability and my accessibility to um significant others for sexual purposes has been diminished. So everything is reduced, you know as you get older your chances of hooking up or picking up somebody are reduces unless you're extremely... wealthy or just period, and just on looks alone you're out of gas son. (Carlos C.) It's a difficult process really, I don't enjoy seeing my appearance change, the grey hairs, the weight gain, the 
wrinkles, and all of that because you know the gay

community can be very intolerant of people over the age of

30 really. Even just in stores or going for services, it

matters. (Bill)

Also, being HIV positive was viewed as contributing to isolation among aging men. Among the seven men who reported being HIV positive, a total of four were concerned that their status would contribute to increased isolation as they aged. Although there were numerous services and organizations available to help them, they felt that their options to build personal connections in the form of intimate partnerships or finding close, supportive friendships as HIV positive individuals was further hampered by their age.

Um as you get older and living with HIV, it is difficult to um... because of the stigma attached to it it's hard to disclose. Because when you disclose your status no matter how healthy you are people are kind of scared of you. They think you have some kind of disease or plague. They treat you like you're diseased and they don't really want to get to know the person. They're just afraid of you. (Scott) Being HIV positive, well, I think you know, I've always seen aging as something that's you know, natural, and welcoming in the age of HIV and AIDS. I welcome old age, but my biggest concern is you know being [HIV positive], how will I be treated, right? Because when you're 
old you're dependent on other people and you're dependent on their kindness. (Alberto)

Negative Health Outcomes. Finally, half of these men reported that fears of negative health outcomes were a concern they associated with aging $(n=10)$. Comments that specifically included the term health were coded under this theme. Of the men that reported these health outcome concerns, seven specifically made statements that poor health is increasingly something they worry about.

Oh, I feel (pause) as an independent person that I have always been... (pause) I feel that, do I have, you know will I be happy with my own self you know if I reached the age of let's say 80, I mean if I'm not healthy you know how am I going (pause) it's a little confusing to be honest with you, I hate not to, you know I hate to think ahead of me but I feel, I think you know one day at a time and I think everything you know has its own grace like in life, so it's ok, I'm mean I'm prepared you know to face you know the future. (Carlos A.)

I just want to... staying healthy... staying healthy and avoiding... avoid being in an assisted living... nursing home kind of thing. [Keeping] out of like Shadow Wood or, um, Broward House. They're shelters for people with AIDS. (Scott) 
The kind of current health conditions do I have, it that could make my old age better if I control them. Or make my old age worse. So in my immediate future is kind of like getting a grasp, getting a grasp of my current health so that I can be the best I can be as I get older. (Alberto) I guess based on my parents situation, what comes to mind is a lot of visit to the doctors and a lot of pain and suffering. And as a person living with HIV for almost 30 years, that is not necessarily new or scary to me. But I just imagine that it will get, you know.... My visits to the doctor will be more frequent, um, and I'm hoping I'm wrong about that. (Fausto)

Those men with access to regular health care, particularly through government or work based insurance programs, had a more positive view of health outcomes. A total of four men reported that they were concerned about their physical health; however, they felt secure it could be addressed given their health insurance options.

Well, health issues yes because the older we get the more issues we're gonna' have. But fortunately all that technology and the medications are getting better so there's gonna' be better treatments I hope. (Immanol)

Ok, um because of the context I live in, I (stammers) was diagnosed [with HIV] in my 20s. And um, so uh (pause) having access to reliable medical care. That has been the 
number one priority in my life. I just turned 50, in July 18 of this year, so um, here in Florida, the services are pretty good- if you are poor or rich. If you are middle class you are screwed, excuse my French. (Fausto)

Yes, I have great health care. And it's basically the Affordable Health care Act that provided it. The Ryan White foundation- it's - not anything that I've really had to pay for or anything or that I've worked for. It's provided to me because of, um, the people that died of AIDS back in the 80 's. They... through ACT UP and those people that died of AIDS they made it possible for me to have health care. (Scott)

\section{Current Health Social Networks.}

To identify these men's current social networks we first coded for social networks that were reported as being a current social network and that were raised as being involved subsequent questions about current health experiences. When specifically thinking about social networks to address aging and health concerns all participants in the study reported having at least one social network. Initially, one participant reported having no social networks; however upon further prompts he did identify two networks. Health care providers $(n=17)$, family and close friends $(n=14)$, gay community spaces ( $n=12)$, and partners $(n=6)$ emerged as the social networks most often reported by these men as the social networks they turned to when addressing health concerns related to aging. 
Health Care Providers. The most cited source of information about the incident and ensuing relationship conflicts were health care providers. Health care providers were coded as any individual or entity that was directly linked to the provision of medical health related services; these included physicians, health clinics, and general medical health care facilities. Most participants associated health care providers as social networks linked to their aging health related issues $(n=17)$.

I can pursue any health concerns that I have, you know? I have a primary health care physician, I go to the dentist, and I'm dealing, I'm still dealing with issues as a result of being hit by a car. [Health care providers] are helping me cope and live. (Bill)

I feel [health care clinic] is so important. They are extremely good because they know me. I trust on them. (Pause) I really consider them as a family because I can tell everything and they are a part of my life. (Eduardo)

However, participants' sexual orientation identification emerged as shaping their degree of satisfaction with health care providers. Having health care providers that valued and accepted their gay identity was helpful in addressing their health concerns according to seven participants. Those men who had positive experiences all associated this experience with being in South Florida $(n=3)$; their responses all noted that these physicians are representative of the region or neighborhood's acceptance of LGBT lifestyles, and high number of gay identified or friendly health care staff. 
As a retiree, we have fantastic health care. We found a local doctor who services the LGBT community, asks us things like "Do you mind if I test you for AIDS since I am taking blood?" No doctor has ever asked me that before. And of course I don't mind- you would want to know. So yes, we found a great health care provider who... who treats us like humans. (Manuel)

The doctors are... down here in South Florida, the doctors are great. A lot of them are gay, some of them are even positive, like of AIDS. [Doctor's name]- he's positive himself. Um [Doctor's name] - is also gay. Um, they're wonderful... they're great doctors. (Scott) I'm pretty open, I made sure as I got older that I found doctors that were more, either, either gay or, or dealt with a gay clientele. So they were more, so that I feel more comfortable saying that. So certainly living in an area like this [gay identified] area has allowed me the opportunity to find doctors that are more used to dealing with our population. (Erik)

However, a total of four expressed disappointment with their interactions with health care providers when they were unable to feel comfortable identifying as gay. This lack of connection over sexual orientation identity emerged as the only reason for difficulties with health care providers within the data. These men noted that this 
disconnection directly affect the quality of service they received, and noted it could have long term effects on their health as they aged.

With doctors sometimes I wish I can [talk about sexual orientation] because it [would be] easier for me to build rapport with the doctor. But sometimes they- I don't know how they going to react you know? They are human beings and they have their way of thinking. And I get afraid. (Isirdro)

[His doctor] know me for a very long time and, I mean he doesn't know [participant is gay]... if that's what you're asking me? No, he doesn't know- he doesn't know that I gay, but it never came up you know..: I mean he doesn't ask it, I mean I had my HIV test, my, you know, the venereal disease. But you know he doesn't ask it. Don't ask don't tell (laughs) right? It's like the army. (Andres)

One of these men did recently tell his new health care provider about his sexual orientation identity because he felt it was necessary if he was to receive proper services. He is aware that the health care providers at this clinic appear to not be comfortable with this, but his partner's HIV status put him in a position where he felt it was necessary to confront the issue head on.

I am gay because [health care providers] needed to know the truth because it's the only way you can have the correct service. Because you if you do- you lie. You don't receive 
the truth. It's important to have (pause) the power or the courage to say to the doctor what is your sexual preference.

Because in my case my partner is HIV positive and we have eight year relationship. But whatever, we have to keep the safety for our relationship, but you never know.

(Leonardo)

Family and Close Friends. Family and close friends were the second most frequently mentioned current social network by these men $(n=14)$. In the present study, family and close friends ended up being discussed interchangeably to include non-blood related individuals and close friends. Given this, family and close friends were grouped together. These men mentioned familial relations (e.g., mother, sister, cousin), or "best friends". Relationships with family and close friends was viewed as instrumental in negotiating psychological and physical health concerns.

Hmm, well I have social relationships with my family- my partner and I have very positive [family] in our lives. We have a lot of support from our own personal families, and uh friends are very supportive about who we are and who we have become as a couple and as individuals. This helps [dealing with aging] a lot. (Clark)

I don't think about it that much, because I, you know, uh my family is pretty, pretty well knows about the situation. I have good friends. I have a partner. So I feel kind of secure that I have someone there to, uh grow old with. (Erik) 
For a Hispanic person, is unheard of, we will always be connected to our parents. Even if they were not so nice. Um, but in the Anglo community I know a lot of people that have not talked to their mother or father for a long time. So that is a main concern. Staying connected with my family to help stay healthy. (Fausto)

Yea, I have family here that lives in Miami. I have friends, and yeah I'm in a recovery program. So I have lots of support and people I connect with. (Rick)

Two participants noted that they had no family or close friends that could be supportive of them. They noted that not having this kind of close support made them feel alone and afraid of aging.

You know I don't have a family. I mean I do have a family back in Colombia. But over here every one passed away already- my friends, my family. All I have is a sister in Connecticut and uh, so I really don't have much to lean on over here, so... (Carlos C.)

Gay Community Spaces. A third social network that emerged as a source for health support among this populations was gay community spaces. This social network was differentiated in the data from others by the fact that they are tangible sites (e.g., organizations, clubs, community groups), or geographic areas (e.g., neighborhoods) that are identified as primarily serving LGBT populations. Based on these criteria, these two spaces often interchangeably referred to in discussions about this type of social network's 
influence as the sites were often located within geographic areas deemed "gay friendly". Together, gay community spaces were social networks used by over half of the participants to navigate aging related health concerns $(n=12)$. For them, living in an identified gay neighborhood also emerged as important in helping these men age positively. A total of six men specifically noted that being surrounded by other members of the LGBT community helped ensure that they would be interacting with people that would not judge them as they age and face various health issues.

Especially living this close to Wilton Manors, the Pride Center- we volunteer in the Stone Wall Museum. We're active in the community. There are so many [health] services for us. So yes, and you feel safe here. As an older gay man. I feel very safe here. (Manuel)

Well fortunately because I live here in Fort Lauderdale. We have many organizations gays and they provide service for people of our sexual orientation. You can I don't feel bad living here. The situation was not this easy when I was living in [suburb in] Miami. (Leonardo) No, that I think what makes my transition really, making it easier, is that when I made a choice to leave California to come to Florida, one of my, um, I would say the attraction to south Florida, and this is where I met my partner who is here in south Florida, is how the elderly seem to live very well and had a very more positive attitude about well, you 
know, the well-being physically, emotionally, and uh, so transitioning to getting older I feel like I have settled into a place where I'm not a minority, I will be a majority, with seniors and gays that are doing well. There is a strong longevity here for people who do well on the conditions of weather and just attitude here, and so I'm looking forward to those senior years. (Clark)

Partners. Partners emerged as the fourth most cited current social network. All six men with partners reported that these relationships were critical for their ability to address health care issues related to aging. The participants saw these social networks as providing instrumental (e.g., help with daily responsibilities, assistance with health tasks), material (e.g., financial, health insurance), and psychological (e.g., companionship, friendship, self-esteem) support.

I am happily in a long term relationship, we've been together now for nine years now, we did a civil union in New Jersey, we haven't found a need for a marriage since we moved here, we have all the legal papers, so nobody can keep me out of the hospital, or do any... when he is wants to die, we have been over that. We had a [marriage] ceremony in New Jersey because that allowed me to get my partners medical benefits when we retire. (Manuel) I know it sounds cliché I married my best friend and that's a great that's a great gift that god has given me. But what 
worries me about the future and I'm very high anxiety. I'm very stress out when it comes to... that you know eventually one of us has to go first. And I think that that's the part of any relationship you know is having to deal with that day- whether it be me or whether it be him. And having to deal with that reality you know I will not have him here forever. I think about it a lot because the older that I get the more you know the more that... (pause) you know (pause) the you know (pause) the way that we... way that we live is just a... the fact that we are alive is a gift especially when you see so many people so many loved ones that are (pause) that are perishing. I worry about my...you know my existence and being alone without him.

\section{(Gregory)}

Two of the men who were currently single reflected on recently ended long term relationships as something that they missed as having part of their social network. These men felt that there was a noticeable void in their current social network that could directly impact their ability to age in healthy ways.

Well, um, I just had a, you know a separation with my partner after 30 years. But at 59 now. I'm really nowhere. I mean it's pretty difficult, um you know, so you know I'm nowhere, I'm basically at home, and figuring things out on 
my own now. It is scary to not have him with me at this

point in my life. (Rick)

I was with my partner for 40 years, since 1975 . Finally we stayed together for 40 years, we got married in January 24, 2015. And he passed on May the 9th of that same year. As we get older...yeah it's harder if you're by yourself, it was a lot easier when I had a partner. We shared expenses and um you know activities, et cetera. (Gustavo)

\section{Desired Health Social Networks}

Participants in the current study spent a considerable amount of time discussing their desired social networks. These idealized networks were viewed as central in improving not only their physical experiences with aging, but also their psychological, interpersonal, and economic wellbeing. The key question that captured responses related to desired social networks was "What is likely to make your transition to older age easier or harder?" The three social networks that emerged as desirable by these men to improve their negotiation of age-related health issues included having a partner $(n=13)$, family $(n$ $=10)$, and gay community spaces $(n=8)$.

Partner. Having a partner was the most commonly reported desired social network among these men $(n=13)$. Not just a friend or sexual partner, these men desired an intimate partner that was identified as their companion. This social network addressed two primarily health concerns reported by these men: finances and isolation. Financial savings was a reason raised by six of the men. In these cases, having a partner provided the men a means to share necessary living expenses like housing, and food, or 
help with retirement plans. Others also reported that it would mean they could engage in more leisure activities if these basic costs were shared.

Who am I going to be getting older with? Will I have a partner who can help me be financially stable and prepared for the day when I do have to retire? You know there's a lot of unanswered questions that I can try to answer but don't. (Bill)

I guess, uh, it will make it easier for me to age with a companion. Definitely everything is easier with (pause) with company or with support. And, um, I think that it is easier for my friends that are married or in long term relationships, it's easier for them to live in terms of finances. (Fausto)

However, the prevailing reason that men reported wanting a partner was for companionship as they aged $(n=9)$. They felt that it would be helpful to have a partner with whom they could share experiences with and build a close relationship at this point in their life. However, most did not expect that this would happen because of their own or others ageist attitudes $(n=6)$.

I don't know if I'm going to have a husband. Because like I was telling you earlier, my, my marketability. I think I missed the bus hypothetically, you know? (Carlos C.)

Well I don't want to be alone... Maybe because of the age again. I'm not accustomed to networking via internet. And I had past 
experiences- negative ones- with all this internet stuff. Not myselfbut friends of mine or partners of mine who were just engaged in this internet stuff. So I really don't like it at all. I prefer to go out and talk to the people and say hello. And not hiding behind a screen or something like that. But that's not how things work now.

(Walter)

Family and Close Friends. Although family and close friends emerged as the second most common utilized current social network in this present study, having greater closeness with family members specifically was desired among half of these men $(n=10)$. Close friends did not emerge as prominently in their responses to the question "What is likely to make your transition to older age easier or harder?" which captured these men's idealized social networks.

The majority of the men reported having a positive relationship with their family $(\mathrm{N}=16)$. They interact with their parents and view their transition to aging as tied to their own. Often participants reflected upon their own parents' experiences to predict their own future outcomes, and expressed a desire to maintain close bonds throughout the aging process with their families as their parents had done.

Right, so, so I, I just, I just think that, uh, being Hispanicwhether you are gay or straight- being there for the parents and being close to parents is something that is, it has a bigger tie than if you are not Hispanic. I think it's more of the way that you were raised. That a lot of times your grandparents lived with you and so on. So that you were 
expected to take care of them. So is now, it's just beginning to be new for [aging parents] to not be living in your house. Uh, so I think that, that, that makes a big difference with aging. (Erik)

However, even among those who had positive relationship with their families, a few desired even greater closeness as it related to their sexual orientation $(n=6)$. Specifically, they were glad that their families accepted them, but raised the point that they could not fully disclose their sexual orientation or openly discuss their experiences, even in cases where they may have long term partners. These were often tied to the families' ethnic identity, generation status beliefs, or the gender of the familial member. In this sample of men, only five men had disclosed their sexual orientation to fathers. In contrast, 15 had come out to their mothers, while 16 were out to their siblings.

They, you know [he is gay] (pause). I've been living with someone for now 16, 17 years. It kind of, like you know, (pause) come to terms, that where they understand the situation. Gut it was never, when you, when you, you- you never had that conversation when you sat down and said, “You know, I'm gay”. But with my partner being Anglo, he had that conversation with his parents, with his family. And he doesn't understand why that isn't happening with mine.

(Carlos A.)

Well [his partner] is younger then me .... But I don't know. I would like to share with you this experience. When his 
parents arrived [from another Latin country] I needed to move to the guest room. Because supposedly his parents doesn't know about the gay situation. (Leonardo) I don't know, I don't think it's just that the gays part, it's in the [Hispanic] culture, you know. You don't tell people that you are (pause) until you're in death bed, or you're dead, you know? You try to hide it more than a non-Hispanic family that's pretty much up front. (Erik) Well coming from a Latin family, I mean, that was a real, you know, difficult thing with my parents and my siblings my uncles and aunts my grandparents, because they came from a generation and place in which in all this was not as acceptable, but now I think, uh, looking back at it, at um, there is still stigmatism towards it against the in the Latino and Latin communities (Clark)

A few men with no family connections or who were not able to fully disclose their sexual orientation status perceived not having the full support of this social network as a void in their lives $(n=3)$. Family was viewed as a safety net for ensuring they would be taken care of, or having a circle of support as they aged. Regret over this was expressed by three men.

So I'm kind of hoping some kind of subsidization takes place for people like me. I mean I don't have a family and I'm not going to have children. I'm not going to have a 
wife... I mean, uh, what comes to mind is I'm scared, yea, I'm scared, I really don't know a better answer, I think I'm scared, I think everyone's scared if they don't have family. But I'm scared for my own particular private lonely reasons. (Carlos C.)

To me being a gay person and getting older is a big problem. I feel rejected for my [gay community identification] by family. So I feel very lonely and I have my concerns about [being along]. I wish I could be closer. Especially at this point in my life. (Isidro)

Gay Community Spaces. The final desired social network that emerged from the data was gay community spaces. Again, this was coded to include are tangible sites (e.g., organizations, clubs, community groups), or geographic areas (e.g., neighborhoods) that were identified as primarily serving LGBT populations or were deemed "gay friendly" by the participants. Living in a gay community space for these men meant they could age without concerns about having their sexual orientation judged. Even if it meant sacrificing quality of life, as one participant noted, it was important to be surrounded by LGBT neighbors, services, and community supports.

The rent, food, medicine including for traveling [to work], whatever but I'm not I'm not sure I don't feel comfortable I don't feel safe in my age living here in United States. And for this I think so many people from United States decide to live the old age in Costa Rica or in another country. 
Because there they are going to have better quality life with a less cost. But my experience wasn't happy because I was living practically living like an island, alone [without gay community resources]. I needed to drive to Miami Beach or I needed to go to Fort Lauderdale or... every time I needed to drive you know sometimes you like to dream to be [living in local gay community] when I get older.

(Leonardo)

Maybe I will live forever in South Florida with people like me. So yeah, that's what I look forward to, to be an old man staring at the ocean-Yemaja! (laughs). (Nubio) And I feel that with everything that is here in south Florida for the elderly and the gay programs that I'm going to be ok. You know? (Clark) I am putting some money aside so that I can plan for the right future. Yea, um, I think that financial security (pause) and an environment where I can grow old at peace (pause). So I'm looking like "Are there other places that I can move to as a gay man?” or "Do I want to stay in Miami?” I mean I'm already thinking about all that stuff (laughs). (Alberto)

\section{Other Aging Related Social Network Concerns}

Three of the seven HIV positive participants also noted that there were additional financial challenges that the gay community should consider when addressing the needs 
of aging gay men. These men pointed out that their financial situations as HIV positive may be unique as the message through the AIDS crisis was that they would not live into their senior years. Thus, programming and services should consider that HIV positive men may need additional help.

I was in NY recently and learned about couple projects for, um, building basically retirement homes for people- gay people. In NY city, because is a new thing. So they are starting to wonder what are we- what are we going to do with all these, eh, older people living with HIV? That are becoming $50,60,70$, and 80 ! I know people with HIV that are 80 . That is completely new. So we need new retirement homes that will cater to my HIV positive community. The special needs of people living with HIV and also taking into account that we are broke. We didn't have retirement plans. We were preparing to die not preparing to live. (Fausto)

Also, three men expressed a desire for greater racial/ethnic diversity within gay community spaces. They noted that these sites were predominately populated by White males; while they did not express resentment, they did express that they often felt like outsiders in the community. They were also concerned with the discrimination they experienced. As one Mexican American participant reported:

Many [White] people in the gay community of Wilton Manors often ask if I am a prostitute or will ask me about 
my legal status. (Eduardo)

There was stigmas against being a Latino or Mexican [in the gay community. When I would go to a [gay] social environments where it was dominantly white, you know? They were well, educated, high income. And you were always looked to... still stigmatized as being something different. Uh from a different culture. And it took a while to me, you know, for me not to feel like I was fitting in [to gay community. In most of the time, in my early days of being gay. I didn’t fit in. (Clark)

However, it was also reported by four that living as gay men in South Florida, and Miami specifically, was difficult. They felt that Hispanic culture was not hospitable to them as sexual minorities. Engaging the Hispanic community often meant that they had to hide their sexual identities, which was viewed as a barrier to being their authentic selves and ability to build social connections with others in Hispanic spaces.

I believe New York people are more friendly. With the gay question, yes with gay- yes in compared to for instance Miami. It is very closed. And uh they because most of the people are Hispanic and the culture is a big obstacle as a gay man. (Nubio)

Well, again living in Miami, the being Latino or the Spanish part, I could fit anywhere. My father is German/Irish, my mother is Spanish, but I grew up in 
Nicaragua. But again in Miami I don't get that feeling too much of [being excluded because of] the Latino part. But umm the gay part definitely yes. I mean I go to the car wash and I see the [Hispanic heterosexual] guys talking connecting, I can do that you know, I'm not, but... Yeah. [Hispanic heterosexual] men connecting with men and you know, I don't have that. (long pause) I don't fit. (Rick) 


\section{DISCUSSION}

\section{Overview}

The purpose of the current study was to shed light on Hispanic gay men's aging related health experiences through an examination of their social networks. Although extensive research has been conducted about this phenomenon in heterosexual populations' experiences and outcomes, the utilization of social networks among aging, gay Hispanic men has been non-existent. Consequently, the findings from the current study contribute to a currently small body of literature that is needed, given the predicted growth of this population in the coming years.

These findings indicate that aging Hispanic gay men utilizing of social networks are consistent with social network theory (Berkman, 2002; Berkman \& Glass, 2002; Simons-Morton Haynie \& Noelcke, 2009). Overall, it was found that study participants viewed social networks as important for and influential on their aging related health outcomes. The availability and usage of social networks for this population are informed by their experiences with age, sexual orientation, ethnicity, and social class status. However, the differing importance of these identities for each man became most salient during their interactions with key health related social networks. In this chapter, the meaning of these results within the context of the broader body of aging, Hispanic, and gay men's health research is presented.

\section{Aging Related Health Concerns}

The first phase of the study identified the key health concerns within this population. The content analysis revealed three broad themes: finances $(n=16)$, followed by loneliness $(n=14)$, and health outcomes $(n=10)$. 
Finances. The concern about finances emerged as the greatest concern these men had related to aging. As they are moving into the phase of chosen or forced retirement, these older gay men's options for increasing financial security diminish. Yet, there is a continued need for ensuring there is money available for routine consumption (e.g., daily living expenses, housing costs), and to protect against financial risks in old age, such as those posed by a severe illness or the death/ loss of a partner. Understandably, the majority of the men were concerned about the way their finances would affect their health as they aged, given the majority had no retirement plan in place. But they are not alone as it is estimated that $43 \%$ of American households are not financially prepared to continue their current standard of living as they age, irrespective of health concerns that are expected to arise (Skinner, 2007).

The link between finances and perceptions of health has been well established in the literature. Research has shown that finances is one of the most consistent predictors of psychological stress during transitions into and stages of retirement (Bossé, Aldwin, Levenson, \& Workman-Daniels, 1991; Osmanovic-Thunström, Mossello, Åkerstedt, Fratiglioni \& Wang, 2016). Further, health changes have the most significant impact on financial stability among older adults in the United States (Coile \& Milligan, 2009). This becomes even more concerning in the current population as the national Health and Retirement Study results indicate that in the next five years, approximately $10 \%$ of older Americans will be devoting more than half of their total income to out-of-pocket health expenses (Skinner, 2007). These men's concerns indicated that this was a current reality for a number of them, even though they were still working and with a median age of 58 were not yet older senior adults. 
The men who were most concerned about financial issues did not have plans to address this reality. They were also expressed that they did not know what to do and just planned to continue working. This approach fits with what the financial literature suggests as the longer one delays retirement, the smaller your retirement savings need to be (Skinner, 2007). However, it does not address the possibility of debilitating or routine health care costs that rise in frequency as people age. For these reasons, health insurance is being counted on by these men; fortunately, the majority of participants have some sort of coverage.

The unknown about what can be done or what typically happens for these men is reflected in the literature as the research on financial stability in older populations is limited. Although several studies have examined housing equity among older adults (see Coile \& Milligan, 2009) few have considered broader financial assets or spending patterns. Further, research on health insurance within this population does explore the impact of government programs such as Medicare or Obama Care (see Kaplan, 2011; Kaufman, 2009), but fails to provide subjective information about individuals' actual health experiences with these programs or without. The ongoing swings in public and private pension and health insurance policies means that future researchers should focus on the ways in which this population negotiates their aging health needs. As this move toward defined contribution plan puts more responsibility on the individual to make retirement financial plans, there is a need to address the specific needs of a population that has unique health issues, desires to reside in specific regions/neighborhoods, and are at a higher risk for not having children available to assist with monetary or instrumental supports. 
Loneliness. Loneliness' emergence as the second most important health concern among this populations supports researcher assertions that it is a common occurrence in aging populations. As people age, there are more opportunities for people to lose connections with their friendship networks (e.g., death, moving in with caretakers/ caretaking facility; Hawkley, Thisted, Masi, \& Cacioppo, 2010). In fact, Adams, Sanders and Auth (2004) found that grieving a recent loss, receiving fewer visits from friends, and having a less extensive social network predicted loneliness. The physical limitations often associated with aging also contributed to individuals' inability to actively participate in the social networks' activities (Hawkley, Thisted, Masi, \& Cacioppo, 2010). With advancing age, it is inevitable that people lose connection with their friendship networks and that they find it more difficult to initiate new friendships and to belong to new networks. This is concerning given number of chronic health conditions increased older individuals risks for loneliness (Adams, Sanders \& Auth, 2004).

Prior research has established a strong link between loneliness and negative health outcomes in older populations. For example, Hawkley, Thisted, Masi, and Cacioppo's (2010) study of middle- and older-age adults, found that lonely individuals reported an increased number of chronic stressors (e.g., financial, work, marital, social, residential, caregiving, and general difficulties in daily life) than did non-lonely individuals. Similarly, it is one of the 3 main factors leading to depression in older adults, and is related to poor psychological adjustment, dissatisfaction with family and increased disconnections to social relationships (Singh \& Misra, 2009).

A key social network that these men felt would help address their concerns about loneliness as an aging concern is the presence of a partner. In the present study, only 30 
percent of the men were in a relationship, while two had recently lost a partner either to death or a break up. All of these partner or recently single men noted that the presence of this support network was instrumental in making them feel safer about facing aging concerns alongside some they loved and trusted. Studies have noted that the presence of a committed partner or spouse increases and individuals mental health, expanded social networks, and positive health outcomes among older populations (Sasson \& Umberson, 2014). For gay men, having a partner in this period of recent political shifts in LGBT rights has also improved psychological well-being. Research has found that psychological distress among gay, lesbian and bisexual individuals has declined significantly among those living in states that have passed legislation advancing LGBT marital legal rights (Fredriksen-Goldsen, \& Espinoza, 2014). This is because legal marriage can provide access to significant health benefits as it means access to health insurance, and spousal and survivor benefits through Social Security (FredriksenGoldsen, \& Espinoza, 2014).

A key barrier to finding a partner in the gay community, according to the men in the current study is ageism. As these men and prior research has noted, attitudes toward the aging body within this population makes dating and finding partners difficult. Specifically, research has shown that gay men give significant value to physical attractiveness and youthful appearances (Barry, 2000; Duggan \& McCreary, 2004; Kaufman \& Chin, 2003; Robinson, 2015). These men even noted that they themselves desire a relationship but also know they tend to gravitate toward the idealized stereotype of the young, healthy man when seeking partners. This attitude then decreases the options for older gay men to find partners within a context that devalues their appearance and 
stage of life (Barry, 2000; Kaufman \& Chin, 2003). Similarly, the spaces for finding partners are frame within youthful contexts (e.g., dance clubs, online dating) which reinforce the importance of looks. Awareness of this phenomenon among these men contributes to their concerns about aging without a partner.

Finally, the men in the study that identified as being HIV positive noted that their status contributed to their feelings of loneliness as they aged. This health issue as tied to perceptions of being stigmatized or isolated from others who may not be infected, despite increased awareness about the disease. Research supports this concern as stigma and isolation has been identified as a major factor affecting the well-being of individuals with HIV (Galvan, Davis, Banks, \& Bing, 2008). These men's fears can lead to internalized stigma; this combined with a willingness to disclose their status puts them at increased risk for isolation, depression and poor health outcomes (Galvan, Davis, Banks, \& Bing, 2008; Okello et al., 2015).

Negative Health Outcomes. According to research aging adults experience multiple co-occurring chronic health conditions which not only lead to death but diminished quality of life, mobility and the ability to perform daily functions requiring help from others (CDC, 2013). As life expectancy has increased in the U.S. aging adults are faced with multiple factors related to chronic health conditions, which over time lead to the inability to perform daily tasks and ultimately are unable to care of their own needs. According to research aging people will likely develop co-occurring chronic conditions affecting their lives in terms of diminished quality of life and decline and disability as they age due to these chronic health conditions. The leading causes of death 
among aging adults include heart disease, cancer, stroke, chronic lower respiratory diseases, Alzheimer's disease and diabetes (CDC, 2013).

One area of focus within the gerontology and developmental research is that of gender disparities for men and women (Gorman \& Ghazal-Read, 2008; Birditt et al., 2012). Older men are less likely to seek medical attention or take preventative health measures as compared to women. As a result these conditions among men become untreatable. (Bertakis, 2000; Hankivsky, 2012). In addition, men are more likely to suffer chronic health conditions such as heart disease, liver disorders, and other life threatening conditions as well as mental disorders (Kim, 2005; Collins, 2008, Vega, 2011; Brown, 2013). To better understand the health care concerns, it is necessary to consider the issue of gender differences in terms of how men and women access health care, and socio-cultural barriers involved in this process (Bertakis, 2000; Hankivsky, 2012). An increased understanding of gender related aging experiences provides insights into the special health needs and challenges of aging men (Nemmers, 2004; Knochel, 2006; Fenk1, 2014).

According to research on gay men's health there are many factors associated with health disparities among this group when compared to heterosexual men. Some of these disparities are related to access to health care and adequate health insurance coverage (Fredriksen-Goldsen et al., 2012). There are significant health related disparities for aging gay men compared to heterosexual men with similar demographic factors in terms of heart disease, hypertension, obesity, diabetes and physical disability. In addition gay men are at higher risk for mental health disorders such as depression and anxiety (Wallace et al., 2011). Gay men are more likely to smoke, engage in alcohol consumption and 
substance abuse related issues which exacerbate chronic health conditions (FredriksenGoldsen et al., 2012). Many of the mental health disorders associated with aging gay men are related to victimization, internalized homophobia and concealment of sexual identity and lack of positive social support, especially in later life (Fredriksen-Goldsen et al., 2012). Moreover, gay men and MSM are highest among people infected with HIV/AIDS in the U.S. (Census, 2014).

According to research race/ethnicity appears to have a profound influence with regard to health disparities and aging (Census, 2014). Minority groups have shorter life expectancy and are less likely to have access to health care and education on prevention (Brown, 2013; Kim, 2005; Vega, 2011). According to research Hispanic people share unique challenges in terms of health disparities when compared with their White nonHispanic counterparts. For example, Hispanic people have higher rates of heart disease, cancer, diabetes, alcoholism, substance abuse and mental illness (Brown, 2013; Kim, 2005; Vega, 2011). Moreover, Hispanic people have higher rates of HIV/AIDS infection when compared with White non-Hispanics and are 2.5 times more likely to be infected than their White non-Hispanic counterparts (Census, 2014). Taken together, aging gay minority men are higher risk for multiple physical and mental health disorders. The intersection of aging, sexual orientation and minority member status contribute to higher risk of substance abuse and decrease in overall health, quality of life and life expectancy.

\section{Health Social Networks}

Aging researchers have shed light on the importance of successful aging and social support. Aging and loss of function is inevitable, however, the impact of strong social networks has been shown to have positive influences on the ways in which people face 
aging and handle related health concerns (Antonucci, 2001). Key variables on successful aging include the interrelated elements of social network supports, both in terms of instrumental support and emotional (Antonucci, 2001; Baltes, 1997, Frazier \& Waid, 1999). Those with fewer social network resources may face increased financial hardships, anxiety, isolation and depression which may have negative effects on overall health and quality of life (Adams \& Blieszner, 1995; Antonucci, 2001; Baltes, 1997, Boaz, 1999; Fenkl, 2014; Frazier \& Waid, 1999). In the present study, partners, family and close friends, health care providers, and gay community spaces emerged as key social networks that aging gay Hispanic men used to negotiate their health concerns. The relevance of each in their lives and within the context of the existing literature is discussed below.

Partners. According to research (Chang, Wray, \& Lin, 2014; Sneed \& Cohen, 2014; Tomaka, 2006; Wu, 2004) as one grows the risk for co-occurring health issues is likely to increase and this is made worse as social isolation increases and one's social networks begin to decrease. It is vital for older adults to have positive interactions and relationships in order to remain healthy, yet this is a challenge as one's social networks decrease as one grows older (Chang, Wray, \& Lin, 2014; Sneed \& Cohen, 2014; Tomaka, 2006; $\mathrm{Wu}, 2004)$. According to research engagement with meaningful social networks has been shown to improve overall physical and psychological health and increase longevity (Marquez et al., 2014 Sneed \& Cohen, 2014; Wu, 2004). Hoonaard (2009) discusses the practical limitations of being single or widowed in old age in terms of financial concerns, and the emotional stress and isolation experienced by older adults. Among older adults research has shown that being in a healthy partnered relationship can ease the burdens of aging in terms of financial concerns and over all physical and 
psychological health. This is especially true among widowed people who must not only adjust to aging, health issues but also financial burdens on their own and adjustment can be extremely difficult. Thus having a partner as one grows older can be quite helpful as a buttress against the challenges of aging and isolation into latter years (Hoonaard, 2009). The importance of being in a partnered relationship as one gets older is an important focus of the current study as it highlights a common area of concern among the subjects of the study.

According to research (Fenkl, 2014; Hoy-Ellis et al., 2016) aging gay men experience unique challenges as they grow older and this is impacted by whether one is in a partnered relationship. It is particularly important to examine this populations' aging experiences as it has been found that at this stage of the lifespan individuals experience increased social isolation, and financial burdens, simultaneous to decreased autonomy, agency and social support (North \& Fiske, 2012; Stone \& McMinn, 2012). Research also indicates how strong social support is a powerful factor against risky self-effacing behaviors, sexual behavior/choices and drug use among aging gay men (Braine et al., 2011; Darbes \& Lewis, 2005; Fenkl, 2014; Fergus, 2009; Kim, 2005; Mayer et al., 2008). Moreover, unlike their heterosexual counterparts, most senior adult gays do not have children (Birditt et al., 2012; Croghan et al., 2014; Gates, 2013) which are traditionally a source of emotional and financial support for many senior adult people (Boaz, 1999; Croghan et al., 2014; Fenkl, 2014; Kurtz, 1999). This factor adds to the importance of being in a partnered relationship as the primary social support among aging gay men. Addressing the importance of partnership among older adults and health outcomes is quite significant as examined in the current study. This information can provide health 
care providers with increased insight into isolation and increased health risk among older adult who are single or widowed (Fenkl, 2014; Hoonaard, 2009). It is necessary for future research to examine the importance of partnered relationships among older adults.

Family and Close Friends. According to research healthy supporting relationships and social networks are vital for overall physical and psychological health among older adults. One of the most important social networks noted across all groups of individuals, including those in the present study, are family and friends. The support of close family has been found to be vital in healthy aging (Baltes, 1998; Boaz, 1999). As gay men age this becomes an ever increasing problem as dependable social networks decrease leaving one vulnerable in ways that their heterosexual counterparts are less likely to experience. According to Croghan et al., (2014) LGBT people often must develop substitutes for family through friendships who often serve as informal caregivers. According to Croghan et al., (2014) one of the primary fears among many aging adults is the possibility of being placed in a nursing home, yet if one has a family caregiver or close friend who provides informal care this can allow one to remain in ones' own home and one's own community thus making these relationships so crucial for aging people without children or extended family. For this reason, it is important to address the unique challenges among aging gay men in terms of maintaining strong dependable and reliable non-kin relationships and the importance of creating strong social networks among close friends.

Unfortunately, aging gay men are vulnerable to possible ostracism from family due to their sexual orientation (Green, 2008; Guerrero, 2013 Guzman, 2005; Peralta et al., 2013; Vega, 2011). This is particularly concerning within ethnic minorities, where 
individuals often rely on family. Hispanic men, in particularly, may face unique challenges in terms of family support in terms of acceptance and being able to seek support from family and must conceal their gay identity or the must not discuss the topic (Almaguer, 1991; Guerrero, 2013; Guzman, 2005; Kurtz, 1999; Moraga, 1993; Peralta et al., 2013; Vega, 2011). These attitudes may stem from Hispanic cultural expectations around masculinity, machismo and gender norms that oppose stereotypic frameworks of gay identities in familial spaces (Almaguer, 1991; Guerrero, 2013; Guzman, 2005; Kurtz, 1999; Moraga, 1993; Peralta et al., 2013; Vega, 2011). For older Hispanic gay men this potential rejection and/or continued ostracism is concerning given the fact that their families may be their only form of support social and emotional support (Almaguer, 1991; Guerrero, 2013; Guzman, 2005; Kurtz, 1999; Moraga, 1993; Peralta et al., 2013; Vega, 2011).

The combination of these negative experiences often lead ethnic sexual minorities to live compartmentalized, double-lives as a means to ensure various social supports remain in their lives (Almaguer, 1991; Guerrero, 2013; Guzman, 2005; Kurtz, 1999; Moraga, 1993; Peralta et al., 2013; Vega, 2011). This silencing, however, can have negative health outcome results (Briane et al., 2011; Crawford, et al., 2002; Dworkin \& Yi, 2005; Fergus \& Darbes, 2009; Friedman et al., 2008; Green, 2008; Herek \& Garnets, 2007; Purdie-Vaughns et al., 2008). Future research on aging ethnic minorities and aging sexual minorities needs to consider the unique challenges facing these minority groups to better identify and remedy these issues to better serve this population. Service providers can identify risk factors and link aging gay Hispanic men 
to resources in the community and provide culturally sensitive care and services which address the special needs and vulnerability of this group.

\section{Health Care Providers.}

Health care providers, by virtue of their skills, education, and training are at the forefront of addressing this populations health needs. Although they were the third most commonly cited social network currently utilized by these men, their role is important to consider as they are able to provide the practical and instrumental resources that these men will need to address their health concerns. This is critically important to consider given members of the LGBT community are more likely than their heterosexual counterparts to experience difficulty accessing health care (Ard \& Makadon, 2012). Research has noted that this issue becomes even more complex when considering older members of the community given their reluctance to address issues that require them to disclose their sexual orientation.

Being able to disclose their sexual orientation to providers was of great importance to these men and shaped their perceptions of their health experiences. This is because their identity as gay men directly informed their health concerns and their personal identities. Cross-cultural knowledge, which aims to enhance personal insight and empathy with people from diverse cultures, enables health care providers to treat and communicate with their clients/patients more effectively (Buchmueller \& Carpenter, 2010). Studies specifically examining the experiences of sexual minorities have noted that LGBT patients report that they often search for subtle cues in the environment to determine acceptance (Eliason 2001). One such example is highlighted by the finding that gay men dislike when health care providers presume that they are heterosexual (Ard 
\& Makadon, 2012). By seeing Hispanic gay men as individuals with unique identities, health care providers are able to create atmospheres of trust and comfort (Buchmueller \& Carpenter, 2010; Durso \& Myer, 2013). As one study participant noted, having his physician integrate his sexual orientation identity into the approaches he used to address the patient's health made this man feel like a "human". Steps toward this may be ensuring that intake forms are inclusive of a range of sexual orientations and gender identities, develop and prominently display non-discrimination policies that include sexual orientation, or ensuring that providers ask open-ended questions, mirroring the terms and pronouns patients use to describe themselves (Buchmueller \& Carpenter, 2010). In terms of gay Hispanic men themselves, there is need for future research to identify factors that can promote their willingness to disclose their status to health care providers. Durso and Myer (2013) did find that LGB individuals' willingness to disclosure their sexual orientation to physicians was tied to their age, level of education, immigration status, medical history, level of internalized homophobia, and degree of connectedness to the LGBT community. Further, the current cohort of LGBT senior population grew up in periods of less social acceptance of their lifestyles and thus may harbor increased fears of stigma and discrimination than their younger counterparts (Ard \& Makadon, 2012). Such fears may become particularly acute when they become less independent and are forced to rely upon the help and advice of health care providers as a supportive social network (Ard \& Makadon, 2012). However, no studies have looked at racial/ethnic-minority populations specifically. Future research should explore how these factors influenced this specific population of gay men and their perceptions of this social networks as supportive during age-related health transitions. 
Gay Community Spaces. As discussed in the literature having social networks and a sense of community is vital for successful aging. Moreover, having positive social networks have been shown to serve as a protective measure as it related to overall physical and psychological health (Adams \& Blieszner, 1995; Antonucci, 2001; Baltes, 1997; Berkman, 2002; Fenkl, 2014; Friedman \& Goldbaum, 2016). According to research one's space and social environment are crucial in terms of aging well. Especially important discussed in the literature is aging in place which demonstrates the importance of growing old in familiar spaces such as one's home and community and to have a sense of agency and decision making over one's life. Aging and loss of function are inevitable, however, the impact of strong social support has been shown to have positive influences on aging well (Adams \& Blieszner, 1995; Antonucci, 2001; Baltes, 1997, Frazier \& Waid, 1999). Key variables on successful aging include the interrelated elements of support, both instrumental support and emotional support (Adams \& Blieszner, 1995; Antonucci, 2001; Baltes, 1997, Frazier \& Waid, 1999). Moreover, the aging population and quality of life often reflect the social and functional aspects of daily living. Much of the support comes from close family, especially children and community spaces (Adams \& Blieszner, 1995; Antonucci, 2001; Baltes, 1997, Boaz, 1999; Croghan et al., 2014; Fenkl, 2014). Those with fewer social resources may face increased financial hardships, anxiety, isolation and depression which may have negative effects on overall health and quality of life (Adams \& Blieszner, 1995; Antonucci, 2001; Baltes, 1997, Boaz, 1999; Fenkl, 2014; Frazier \& Waid, 1999).

Aging and having a sense of community is especially important for aging gay adults and this includes having social networks and public spaces where one can feel safe 
and develop positive supportive relations. Research indicates that social support provide protective factors against isolation, depression, risky self-effacing behaviors, sexual behavior/choices and drug use among aging gay men. Moreover health information, screening for HIV/AIDS and substance abuse treatment can be facilitated through public spaces where gay men feel safe and among other aging gay men (Braine et al., 2011;

Darbes \& Lewis, 2005; Fenkl, 2014; Fergus, 2009; Green, 2008; Kim, 2005; Mayer et al., 2008). The current study provides service providers with important insights into how the aging gay community can be better served through gay friendly spaces and can better reach this population with health related services, and improved social networks toward aging successfully.

\section{Other Aging Related Social Network Concerns}

HIV Status. It is also important to note that these aging gay men share experiences of having lived through the worst of the HIV/AIDS epidemic in during the years 1987-1996 (Johnson, 1992; Rupp, 1999; Jay, 2000; Dworkin \& Yi, 2003; Mayer, et al., 2008; Fenkl, 2014). As noted in the research, this cohort experience has had a profound psychological and social effect on these men's perceptions of health and social networks supports (Ahmad \& Bhugra, 2010; Alden \& Parker, 2005; Hansson, 1990; Herek \& Garnets, 2007; Rosenfeld et al., 2008). Much of their cohort simply vanished before them during the time they were growing up or coming of age as young gay men (Rosenfeld et al., 2008) leaving lasting psychological scars. For many gay men and especially aging men the importance of social networks is paramount; research has noted that supportive social networks have multiple benefits to health and lowering risky behaviors and infection risk 
(Briane et al., 2011; Fergus \& Darbes, 2009; Green, 2008; Purdie-Vaughns \& Eibach, 2008).

Homophobia in the Hispanic Community. The concerns of these men about homophobia within the Hispanic community is an important consideration given that research shows these experiences can to have an adverse effect on overall physical and mental health. The experiences of minorities in the U.S. are often highlighted by discrimination, bigotry, diminished access to resources and lower social status (Brown, 2013; Purdie-Vaughns et al., 2008; Sidanius \& Pratto, 1999). Homophobia within the Hispanic community is an important consideration given that the research shows that victimization, internalized homophobia and concealment of identity can have adverse effects on overall physical and mental health for gay Hispanic men (Bonilla \& Porter, 1990). One factor that influences homophobia within the Hispanic community is that of religion and the moral constructs associated with homosexuality and its condemnation within much of Latin America and among Hispanic communities in the U.S. (Bonilla \& Porter, 1990). Moreover, homophobia in Hispanic communities is associated with the attrition of rigid gender roles and the loss of male control, privilege and power and thus serves as a defense against such societal challenges to these norms and perceived threat to traditional family structures (Bonilla \& Porter, 1990).

Another cultural element which contributes to homophobia within Hispanic communities is the concept of machismo, which refers to rigid standards of gender norm expectation among Hispanic men (Bonilla \& Porter, 1990). Hispanic men are expected to be masculine, dominant, virile and heterosexual (Almaguer, 1991; Kurtz, 1999). Gay Hispanic men are expected to conform to these expectations of masculinity and fear 
ostracism if they do not (Bonilla \& Porter, 1990). Family is another important factor which relates to rejection of homosexuality in the Hispanic community (Almaguer, 1991; Kurtz, 1999). Men in Hispanic communities are expected to marry and produce children and this pressure to conform to this expectation is transmitted by the fathers and mothers of Hispanic children (Almaguer, 1991; Kurtz, 1999). Men who are not married and do not have children in this context are viewed as failures and inferior to men who do meet such familial expectations (Bonilla \& Porter, 1990). Economic factors also play a role with regard to homophobia in Hispanic communities. Hispanic men often occupy lower economic status and experience higher rates of unemployment in the U.S. while at the same time Hispanic women have increasingly entered the workforce which contributes to their diminished sense of control, power and the ability to support their families, which is an important expectation among Hispanic men (Bonilla \& Porter, 1990). Moreover, Hispanic men are less likely to support civil liberties and policies which contribute to the equality of LGBT people when compared with White non-Hispanic communities in the U.S. (Bonilla \& Porter, 1990). Taken together homophobia is strong force among many Hispanic communities, thus gay Hispanic men are under great pressure to conceal their identity and often internalize homophobic discourses which contributes to diminished social networks of support and a litany of physical and mental health disorders (Almaguer, 1991; Bonilla \& Porter, 1990; Kurtz, 1999).

Racism in the Gay Community. Racism is a persistent factor in the U.S. and the discrimination and victimization associated with racism are strong predictors of poor physical and mental health among minorities (CDC, 2014). According to research systematic racism is reflected from the larger society and permeates into gay 
communities in the U.S. (Green, 2008; King, 2004). Gay minority members are often confronted with discrimination and marginalization within White non-Hispanic communities (Giwa, \& Greensmith, 2012). This relates to diminished access to resources, diminished social networks and lower status within the larger gay community (Giwa, \& Greensmith, 2012). Moreover, LGBT ethnic minorities are often rendered invisible within the larger gay communities and have a strong sense of being perceived as outsiders (Giwa, \& Greensmith, 2012). Ethnic minorities within the larger gay community context face an added degree of stigma and isolation and in some cases are sexually objectified and not treated with the same degree of respect or dignity afforded to their gay White non-Hispanic counterparts (Giwa, \& Greensmith, 2012; Green, 2008; Guzman, 2005; King, 2004; Kurtz, 1999; Loiacano, 1989). Given these perceptions of exclusion, minority gay men often feel the need to seek approval from their gay White non-Hispanic counterparts and must negotiate multiple layers of systemic bigotry and racism which persists in gay communities in the U.S. and this is especially true for African Americans and Hispanics (King, 2004; Loiacano, 1989). Historically gay enclaves have provided a bastion of protection and sense of community and freedom from heteronormativity for LGBT people, but this is not often extended to ethnicminority LGBT people who experience double-minority status (Giwa, \& Greensmith, 2012; Loiacano, 1989).

Green (2008) found that gay ethnic men perceive their subordinated status and lower sexual status among the mostly White non-Hispanic community and internalize these discourses. As such gay ethnic men with low sexual status faced significant stressors and have been found to have lower self-esteem, sense of social support, and 
sense of control, this in turn leads to risky sexual behavior in the pursuit of acceptance from the larger White non-Hispanic community. Studies have noted that gay ethnic men are often unable to consistently negotiate condom use as a consequence of a history of field stressors and diminished self-esteem (Almaguer, 1991; Darbes \& Lewis, 2005; Green, 2008; Kurtz, 1999).

Another factor related to racism and discrimination within gay communities as it relates gay ethnic minorities is socioeconomic status (Giwa, \& Greensmith, 2012; Loiacano, 1989). When compared with their gay White non-Hispanic counterparts, gay ethnic-minority members often occupy lower socioeconomic status which contributes to their alienation and perceive inferior status among White non-Hispanic gays (Giwa, \& Greensmith, 2012; Loiacano, 1989). Perceptions of rejection and ostracism are common among gay ethnic minorities within gay communities in the U.S. and this includes public spaces, LGBT community centers, bars and other locations frequented by predominately gay White non-Hispanic people throughout many gay enclaves and gay communities in the U.S. (Giwa, \& Greensmith, 2012; Loiacano, 1989). Moreover, research indicates that social services organizations and organizations which cater to the gay community often lack adequate culturally sensitive training to deal with gay minority men (Giwa, \& Greensmith, 2012; Loiacano, 1989). Taken together the realities and experiences of gay ethnic minorities translates into decreased access to social networks, social services and support within the larger gay community, which in turn leads to lower self-esteem, isolation, depression, self-deprecating behaviors, increased risk for HIV/AIDS infection, substance abuse and increased risk of physical health problems (Ahmad \& Bhugra, 2010; Braine et al., 2011; Green, 2008; Guzman, 2005; Kurtz, 1999; Loiacano, 1989). For this 
reason comprehensive culturally sensitive training and counter measures regarding homophobia are needed within the larger gay community context. 


\section{CONCLUSION}

\section{Limitations}

Although the current study provides foundational research information about an understudied population and phenomenon, there are limitations must be discussed. First, it is necessary to consider social desirability bias. This occurs when research study participants give positive self-descriptions in an attempt to appear that they are engaging in socially normative behaviors, or to please the researcher (Paulhaus, 2002). Studies have noted that individuals who attempted to portray themselves favorably exhibited elevated levels of extraversion, emotional stability, agreeableness, conscientiousness, and openness to experience (Paulhaus, 2002). In the present study, this may have been triggered by the fact that the interviews occurred in a face to face setting, and the interviewer has shared similar identity traits. Although research suggests interviewers and interviewees similar identities can enhance the interview process and increase openness (Few, Stephens \& Rouse- Arnett, 2003), the participants' and interviewer's ethnic, gender and sexual orientation similarities could have influenced men's willingness to fully share their health experiences and increase the likelihood they gave socially desirable responses (Few, Stephens \& Rouse- Arnett, 2003). There may have been concerns that the researcher would know members of their social networks, despite assurances for confidentiality. In fact, the noted conversational pauses, laughter, and occasions of stuttering may be reflective of their discomfort with being interviewed and desire to provide socially appropriate responses.

Similarly, there is a need for increased depth in questioning about the quality and quantity of the social network interactions. For example, the questions did not probe 
about the amount of time and strength of the relationship between the participants and the various social networks. While it was beyond the scope of the study and would have been time consuming given the amount of data being collected, it means that a potential body of knowledge about the methods and frequency of utilization these men engaged in with these social networks is needed. Future work should tease out perceptions of these social networks in this manner and separately examine the experiences based upon these responses. The current study is also limited by the subject's willingness to disclose their sexual orientation. People in society who indentify as gay/bisexual but who cannot disclose their identity cannot be measured by the current study and this is an additional limitation.

A final methodological consideration would be that these data were collected at one point in time. Therefore, the current study cannot address what factors influenced their selection of current social networks, nor can we predict what future networks they will actually utilize. It would be helpful if a future study revisit these participants to gather comparative data about their experiences with social networks 10 years from now. At this point their networks may have gone through significant changes (e.g., deaths, closing of organizations, having to relocate, and stage of openness about sexual orientation) that would change their perceptions and utilization of each. Further, the men themselves would be older and could be experiencing very different health concerns. The social networks they call upon may not be the same depending on their needs at that time.

There are also demographic limitations that must be considered. For example, the majority of participants reported residing within communities that were identified as "gay friendly" at the time of the interview. Although they may have lived outside these areas 
prior to the interview, their current residential location may have influenced their perceptions of social networks specific to their needs as gay men. Further, given that the areas where the men live have such a large LGBT population, there is the real possibility of increased availability of relevant services. This would directly shape respondent perceptions of aging and health experiences. It would be important that future research recruits larger numbers of Hispanic gay men who are not residing in these types of communities as they may have differing recollections and experiences with social networks they utilize for health and aging concerns. Further, these men lived a region where over 33\% of the population is over the age of 50 (Census, 2014). As such, the findings may not be applicable to those living outside of the region where this research took place. Future research must be attuned to these important within group differences when studying aging Hispanic gay male populations.

\section{Practical Implications.}

Despite these limitations, the results from the current study can provide researchers, clinicians and public policy leaders with information that can help them better meet the needs of aging gay Hispanic men. Researchers working with this or similar populations can now better identify what issues need to be measured and assessed. Qualitative research often serves as the foundation for quantitative measurement design (Babbie, 2005; Berg, 2006; Charmaz, 2006). In the present case, there are no quantitative measures assessing aging health experiences that have been primarily developed for racial/ethnic-minority populations. The current study opens the door for researchers to quickly identify what must be asked and ensure the psychometrics that are based upon this or similar population. 
As the current study reinforces prior research findings that show older gay racial/ethnic men may be reluctant to address issues that require them to disclose their sexual orientation (Almaguer, 1991; Clover, 2006; Durso \& Myer , 2013; Eliason \& Schope, 2001; Fenkl, 2014; Hinchliff \& Gott, 2011; Knochel et al., 2010) clinicians can begin to seek ways to address this. This could include now seeking out approaches to creating a culturally competent health check list that integrates their specific ethnic and sexual orientation concerns. It is also asserted that just having this information can increase health care providers' awareness of their own biases and behaviors when interaction with this and other marginalized populations. Research suggests that simple exposure to clients' or other individuals experiences and concerns can increase ones own humility and desire to ensure their interactions are comfortable (Croghan et al., 2014; Dovidio \& Gaertner, 2010; Eliason \& Schope, 2001; Kaufman, 2009\).

Finally, public policy development can benefit from this knowledge when issues related to short-term and long-term health care policies and funding. An increased understanding of aging experiences of gay/bisexual ethnic minorities can provide insights into the special health needs and challenges of this growing population and can provide public policy makers with important insights in order to meet the needs of aging Hispanic gay/bisexual population through culturally sensitive services and health-related resources (Fenkl, 2014; Knochel et al., 2010; Nemmers, 2004). As Fenkl (2014) discusses, the greatest risk to gay/bisexual men is due to the dearth of scientific information about their health and the limited information related to patient centered outcomes. According to research on aging gay/bisexual Hispanic men, an increased understanding of the challenges of this growing population is needed among policy makers when decisions are 
being made and how these decisions impact this population in terms of overall health, economic stability, access to culturally sensitive health care, information about how to receive help, and mental-health (NHCOA, 2013). An increased awareness is needed to address the status of aging gay/bisexual Hispanic men to help policy makers make decisions based on specific needs, major health issues, developing education, and interventions to improve the quality of life for aging gay/bisexual Hispanic men. The current study addresses the lack of research on aging gay/bisexual Hispanic men and helps to identify issues which can lead to more responsible policy making. Early interventions and responsive social service programs can address these issues and mitigate the long-term cost associated with the potential risks and challenges for aging gay/bisexual Hispanic men.

Research asserts the need for policy makers, social service providers and health care providers to address the needs of aging gay/bisexual Hispanic men from a holistic approach focusing on economic status, eligibility for government benefits and help with the process of applying for government benefits, employment, overall health, housing situation, immigration status, language proficiency, social and recreational needs, experiences of discrimination in relation to sexual orientation or gender identity and lastly, care giving relationships in the life of the individual. The multiple factors can help guide policy makers to address the needs of aging gay/bisexual Hispanic men (NHCOA, 2013). Social service providers, policy makers and health care providers are encouraged to develop targeted outreach strategies to better serve aging gay/bisexual Hispanic men and to provide bilingual services and diverse staff members at social service 
organizations to develop trust and increase the likelihood that members will engage with and seek help from these organizations (NHCOA, 2013).

Further, policy development needs to focus on behavioral issues associated with aging gay/bisexual Hispanic men to address and provide education on risky sexual behaviors and alcohol and drug abuse (Braine et al., 2011; Darbes \& Lewis, 2005; Green, 2008; Kim, 2005).

Given the increased number of aging minority populations in the U.S., addressing the needs of this population is necessary for policy makers and social service providers. For this reason the current study can provide health care providers, social service workers and policy makers with important insights in response to a growing diverse aging population in the U.S.

\section{Study Contributions and Conclusion}

The current study provides new insights regarding older Hispanic gay men's experiences with social networks they utilize for addressing aging related health concerns. Participants' current health concerns were framed within discussions about long term health outcomes. The first key health concerns they men had were finances and loneliness. Actual physical ailments emerged as the last significant theme. Currently, the men are turning to health care providers, family and close friends, gay community spaces, and partners to navigate their aging related health concerns. Their experiences with this social networks are influenced by their current health status (e.g., HIV positive), the degree to which they are open about their sexuality, and socio-economic status. Interestingly, when thinking about the future and their aging concerns, the social networks these men most desired was an intimate partnership. Having a partner was seen 
as an important source of companionship and financial support. Family was also viewed as important for providing emotional support, followed by gay community spaces. There was clear concern about the ways in which their ethnic identity, inclusion in gay identified spaces, current health status, and financial stability would inform their experiences with these as they age.

These findings enhance our knowledge about a significantly understudied population, who are members of the largest group of ethnic minorities aging in the United States (NHCOA, 2013). This knowledge contributes to our ability to understand the process by which Hispanic gay men come to experience and utilize social networks at the interpersonal and community level. The results contribute to the development of intervention programs aimed at this population, which may be particularly important given their unique partnership, social services and health experiences (e.g., HIV status). This also points to the need for future research to specifically assess aging and social networks its impact on sexual minorities in the United States. 


\section{REFERENCES}

American Psychological Association. (2016). Lesbian, gay bisexual and transgender aging. Retrieved from http://www.apa.org/pi/lgbt/resources/aging.aspx

Adams, R.G., Blieszner, R. (1995). Aging well with friends and family. The American Behavioral Scientist (Beverly Hills), 39(2), 209-224.

Afable-Munsoz, A., Mayeda, E. R., Perez-Stable, E. J., \& Haan, M. N. (2013). Immigrant generation and diabetes risk among Mexican Americans: The Sacramento area Latino study on aging. American Journal of Public Health, 103, SE2.

Ahmad, S., \& Bhugra, D. (2010). Homophobia: An updated review of the literature. Sexual \& Relationship Therapy, 25(4), 447-455.

Albeda, R., B., Schneebaum, A., Gates, G. J.... (2009). Poverty in the lesbian, gay, and Bisexual. The Williams Institute, UCLA School of Law. Retrieved from http://williamsinstitute.law.ucla.edu/wp-content/uploads/Albelda-BadgettSchneebaum-Gates-LGB-Poverty-Report March-2009.pdf

Al Hazzoiuri, A. Z., Haan, M. N., Osypuk, T., Abdou, C., Hinton, L., \& Aiello, A. (2011). Neighborhood socioeconomic context and cognitive decline among older Mexican Americans: Results from the Sacramento area Latino study on aging. American Journal of Epidemiology, 174, 423-431.

Alden, Helena L., Karen F. Parker. (2005). Gender role ideology, homophobia and hate crime: Linking attitudes to macro-level anti-gay and lesbian hate crimes. Deviant Behavior 26(4), 321-343.

Alegria, M., Sribney, W., \& Mulvaney-Day, N. E. (2007). Social cohesion, social support and health among Latinos in the United States. Social Science \& Medicine, 64(2), 477- 495.

Almaguer, T. (1991). Chicano men: A cartography of homosexual identity and behavior. A Journal of Feminist Cultural Studies, 3, 75-100.

Antonucci, T. C. (2001) Social relations: An examination of social networks, social support, and sense of control. In J. E. Birren \& K. W. Schaie (Eds.), Handbook of the psychology of aging (5th ed., pp. 427-453). San Diego, CA: Academic Press.

Ard, K. \& Makadon, H. (2012). Improving the Health Care of Lesbian, Gay, Bisexual and Transgender (LGBT) People: Understanding and Eliminating Health Disparities. The Fenway Institute, Boston, MA

Arreola, S. G. (2013). Structure, agency, and sexual development of Latino gay men. The Journal of Sex Research, 50(3-4), 392-400. 
Babbie, E. R. (2005). The basics of social research. Belmont, CA: Thomson/Wadsworth.

Baltes. (1997). On the incomplete architecture of human ontogeny: Selection, optimization, and compensation as foundation of developmental theory. The American Psychologist, 52(4), 366-380.

Barry, A. (2000). Age Preferences among Gay and Bisexual Men. GLQ: A Journal of Lesbian and Gay Studies, 6, 413-33.

Berkman, L. F. (2002). Social support, social networks, social cohesion, and health. Social Work Health Care, 31, 3- 14.

Berkman, L. F., \& Glass, T. (2000). Social integration, social networks, social support, and health. In L. F. Berkman \& I. Kawachi (Eds.), Social epidemiology (pp. 137173). New York: Oxford University Press.

Berg, Bruce. (2006). Qualitative research methods for the social sciences. Upper Saddle River, NJ. Allyn \& Bacon.

Bertakis. (2000). Gender differences in the utilization of health care services. The Journal of Family Practice, 49(2), 147-152.

Birditt, K. S., Antonucci, T. C., \& Tighe, L. (2012). Enacted support during stressful life events in middle and older adulthood: An examination of the interpersonal context. Psychology and Aging, 27(3), 728-741.

Black, D., Gates, G., Sanders, S., \& Taylor, L. (2002). Why Do Gay Men Live in San Francisco? Journal of Urban Economics, 51(1), 54-76.

Bloor, M. \& Wood, F. (2006). Keywords in Qualitative Methods: A Vocabulary of Research Concepts. London: SAGE Publications.

Boaz, R. F. (1999). The transfer of resources from middle-aged children to functionally limited elderly parents: Providing time, giving money, sharing space. The Gerontologist, 39(6), 648-65.

Bonilla, L., \& Porter, J. (1990). A Comparison of Latino, Black, and Non-Hispanic White Attitudes Toward Homosexuality. Hispanic Journal of Behavioral Sciences, 12(4), 437-452.

Bossé, R., Aldwin, C. M., Levenson, M. R., \& Workman-Daniels, K. (1991). How stressful is retirement? Findings from the Normative Aging Study. Journal of Gerontology, 46(1), 9-14 
Braine, N., Acker, C. J., Sluytman, L. V., Friedman, S., \& Jarlais, D. D. (2011). Drug Use, Community Action, and Public Health: Gay Men and Crystal Meth in NYC. Substance Use \& Misuse, 46(4), 368-380.

Brown, T. H., \& Hargrove, T. W. (2013). Multidimensional Approaches to Examining Gender and Racial/Ethnic Stratification in Health. Women, Gender, and Families of Color, 1(2), 180-206.

Buchmueller, T, \& Carpenter, C. S. (2010). Disparities in health insurance coverage, access, and outcomes for individuals in same-sex versus different-sex relationships, 2000-2007. American Journal of Public Health, 100(3), 489-95.

Callanan, V. J. (2012). Gender differences in suicide methods. Social Psychiatry and Psychiatric Epidemiology, 47(6), 857-869.

Case, K. A. (2014). Reflecting on heterosexual and male privilege: Interventions to raise awareness heterosexual and male privilege. Journal of Social Issues, 70(4), 722740 .

Cass, V. C. (1984). Homosexual identity formation: Testing a theoretical model. The Journal of Sex Research, 20(2), 143-167.

Castells, M. (2004). The Power of identity. Hoboken, NJ: Wiley-Blackwell.

Centers for Disease Control and Prevention. (2008). HIV/AIDS among Hispanics/Latinos fact sheet. Retrieved from http://www.cdc.gov/hiv/hispanics/resources/factsheets/hispanic.htm

Center for Disease Control and Prevention. (2013). The State of Aging and Health in America. Retrieved from http://www.cdc.gov/features/agingandhealth/state_of_aging and_health_in_america_2013.pdf

Center for Disease Control and Prevention. (2014). Summary health statistics for U.S. adults: National health interview survey. Retrieved from http://www.cdc.gov/nchs/data/series/sr_10/sr10_260.pdf

Chang, P., Wray, L., \& Lin, Y. (2014). Social relationships, leisure activity, and health in older adults. Health Psychology, 33(6), 516-523.

Charmaz, K. (2006). Constructing grounded theory: A Practical guide through qualitative analysis. London. Sage Publications. 
Chu, Y., Porche, M. V., \& Tolman D. L. (2005). The adolescent masculinity ideology in relationships scale: Development and validation of a new measure for boys. Men and Masculinities, 8 (1), 93-115.

Clover, D. (2006). Overcoming barriers for older gay men in the use of health services: A qualitative study of growing older, sexuality and health. Health Education Journal, 65(1), 41-52.

Cohen, E. S. (2001). The Complex Nature of Ageism: What Is It? Who Does It? Who Perceives It? The Gerontologist, 41(5), 576-577.

Cohn, D. \& Taylor, P. (2010). Baby Boomers Approach 65 Glumly: Survey findings about America's Largest Generation. Pew research center social and demographic trends. Retrieved from http://www.pewsocialtrends.org/2010/12/20/babyboomers-approach-65-glumly/

Coile, C. \& Milligan, K. (2009), how household portfolios evolve after retirement: The effect of aging and health shocks. Review of Income and Wealth, 55, 226-248.

Collins, D. (2008). Crossing borders, crossing cultures: Barriers to communication about cancer prevention and treatment along the U.S./Mexico border. Patient Education and Counseling, 71(3), 333-339.

Connell, R. (1995). Masculinities. Berkeley: University of California Press.

Courtenay, W. H. (2000). Constructions of masculinity and their influence on men's wellbeing: A theory of gender and health. Social Science \& Medicine, 50(10), 13851401 .

Crawford, I., Allison, K. W., Zamboni, B. D., \& Soto, T. (2002). The influence of dual-identity development on the psychosocial functioning of African American gay and bisexual men. Journal of Sex Research, 39(3), 179-89.

Croghan, C. F., Moone, R. P., \& Olson, A. M. (2014). Friends, Family, and Caregiving Among Midlife and Older Lesbian, Gay, Bisexual, and Transgender Adults. Journal Of Homosexuality, 61(1), 79-102.

Cross, M., \& Epting, F. (2005). Self-Obliteration, Self-Definition, Self-Integration: Claiming A Homosexual Identity. Journal of Constructivist Psychology, 18(1), 53-63.

Cross, W. E., Parham, T. A, \& Helms, J. E. (1991). The stages of black identity development, Nigrescence models. In R. Jones (Ed.), Black psychology (pp. 319338). Berkeley, CA, Cobb \& Henry Publishers. 
Darbes, L. A., \& Lewis, M. A. (2005). HIV-specific social support predicts less sexual risk behavior in gay male couples. Health Psychology, 24(6), 617-622.

Denby, R. W. (2014). Male kinship caregivers: Do they differ from their female counterparts? Children and Youth Services Review, 46, 248-256.

Denzin, N.K., \& Lincoln, Y. S. (2000). Handbook of qualitative research. Thousand Oaks, CA: Sage Publications.

Department of Health and Human Services. (2014). Administration on Community Living. Administration on Aging, Aging Intergrated Database (AGID). Retrieved from http://www.agid.acl.gov

Dovidio, J. F., \& Gaertner, S. L. (2010). Intergroup bias. In S. T. Fiske, D.T. Gilbert, \& G. Lindzey (Eds.), Handbook of Social Psychology (pp. 1084-1121). Hoboken, NJ: Wiley.

Duggan, S. J., \& McCreary, D. R. (2004). Body image, eating disorders, and the drive for muscularity in gay and heterosexual men. Journal of Homosexuality, 47, 45-58.

Durso, L. E., \& Meyer, I. H. (2013). Patterns and predictors of disclosure of sexual orientation to health care providers among lesbians, gay men, and bisexuals. Sexuality Research \& Social Policy, 10(1), 35-42.

Dworkin, S. H., Yi, H. (2003). LGBT identity, violence, and social justice: The psychological is political. International Journal for the Advancement of Counseling, 25(4), 269-279.

Eliason, M. J., \& Schope, R. (2001). Does “Don't ask don't tell” apply to health care? Lesbian, gay, and bisexual people's disclosure to health care providers. Journal of the Gay and Lesbian Medical Association, 5(4), 125-34.

Erdley, S. D., Anklam, D. D., \& Reardon, C. C. (2014). Breaking Barriers and Building Bridges: Understanding the Pervasive Needs of Older LGBT Adults and the Value of Social Work in Health Care. Journal of Gerontological Social Work, 57(2-4), 362-385.

Erikson, E. H. (1980). Identity and the life cycle. New York: Norton.

Eschbach, K. (2004). Neighborhood Context and Mortality among Older Mexican Americans: Is There a Barrio Advantage? American Journal of Public Health, 94(10), 1807-1812.

Families U.S.A. (2014). Latino health disparities compared to non-Hispanic whites. 
Retrieved from http://familiesusa.org/product/latino-health-disparities-compared-nonhispanicwhites\#sthash.7b3SM2It.J2KN7ujy.dpuf

Fenkl, E. A. (2014). Optimistically engaging in the present: Experiences of aging among gay men. SAGE Open, 4(3).

Fergus, S., Lewis, M. A., Darbes, L. A., \& Kral, A. H. (2009). Social Support Moderates the Relationship Between Gay Community Integration and Sexual Risk Behavior Among Gay Male Couples. Health Education \& Behavior, 36(5), 846-859.

Few, A.L., Stephens, D.P., \& Rouse-Arnett, M. (2003). Sister-to-sister talk: Transcending boundaries and challenges in qualitative research with Black women. Family Relations, 52, 205-215.

Florida Legislature Office of Economic and Demographic Research. (2014). Florida's Economic Future \& the Impact of Aging. Retrieved from:

http://edr.state.fl.us/Content/presentations/economic/FlEconomicFuture \& theImpa ctofAging_3-17-14.pdf

Frazier, L. D., \& Waid, L.D. (1999). Influences on anxiety in later life: The role of health status, health perceptions, and health locus of control. Aging \& Mental Health, $3(3), 213-220$.

Fredriksen-Goldsen, K. I., Emlet, C. A., Kim, H., Muraco, A., Erosheva, E. A., Goldsen, J., \& Hoy-Ellis, C. P. (2012). The Physical and Mental Health of Lesbian, Gay Male, and Bisexual (LGB) Older Adults: The Role of Key Health Indicators and Risk and Protective Factors. The Gerontologist, 53(4), 664-675.

Fredriksen-Goldsen, K. I., \& Espinoza, R. (2014). Time for Transformation: Public Policy Must Change to Achieve Health Equity for LGBT Older Adults. Generations, 38(4), 97-106.

Fredriksen-Goldsen, K. I., Simoni, J. M., Kim, H.-J., Lehavot, K., Walters, K. L., Yang, J., \& Hoy-Ellis, C. P. (2014). The Health Equity Promotion Model:

Reconceptualization of Lesbian, Gay, Bisexual, and Transgender (LGBT) Health Disparities. The American Journal of Orthopsychiatry, 84(6), 653-663.

Friedman, F. B., \& Goldbaum, C. S. (2016). Experiential learning: Developing insights about working with older adults. Clinical Social Work Journal, 44(2), 186-197.

Friedman, M. S., Marshal, M. P., Stall, R., Cheong, J. W., Wright, E. R. (2008).Gayrelated development, early abuse and adult health outcomes among gay males. AIDSand Behavior, 12(6), 891-902. 
Galvan, F., Davis, M., Banks, D., \& Bing E. (2008). HIV stigma and social support among African Americans. AIDS Patient Care and STDs, 22, 423-436.

Garcia, B. (1998). The development of a Latino gay identity. New York. Routledge.

Gates, G. J. (2011). How many people are Lesbian, Gay, Bisexual and Transgender? UCLA: The Williams Institute. Retrieved from: https://escholarship.org/uc/item/09h684x2

Gates, G. J. (2013). LGBT parenting in the United States. UCLA: The Williams Institute. Retrieved from: http://williamsinstitute.law.ucla.edu/wp content/uploads/LGBT-Parenting.pdf

Gates, G. J. (2013). LGBT Adult Immigrants in the United States. UCLA: The Williams Institute. Retrieved from: https://williamsinstitute.law.ucla.edu/research/census-lgbt-demographicsstudies/us-lgbt-immigrants-mar-2013/

Gbrich C. (2007). Qualitative Data Analysis: An Introduction. London: Sage Publications.

Geertz, C. (1973). Interpretations of culture: Selected essay. New York. Basic Books.

Geiger, J. R. (2015). Burden among male Alzheimer's caregivers: Effects of distinct coping strategies. American Journal of Alzheimer's disease and Other Dementias, 30(3), 238-246.

Giwa, S., \& Greensmith, C. (2012). Race Relations and Racism in the LGBTQ Community of Toronto: Perceptions of Gay and Queer Social Service Providers of Color. Journal of Homosexuality, 59(2), 149-185.

Gorman, B. K., \& Read, J. G. (2006). Gender Disparities in Adult Health: An Examination of Three Measures of Morbidity. Journal of Health and Social Behavior, 47(2), 95-110.

Grant, J. (2010). Outing Age 2010: Public policy issues affecting lesbian, gay, bisexual and transgender elders. Retrieved October 23, 2016, from http://www.thetaskforce.org/downloads/reports/reports/outingage_final.pdf

Green, A. I. (2008). Health and Sexual Status in an Urban Gay Enclave: An Application of the Stress Process Model. Journal of Health and Social Behavior, 49(4), 436451. 
Green, J \& Thorogood, N. (2004). Analysing qualitative data. In D. Silverman (Ed.). Qualitative Methods for Health Research (pp. 173- 200). London: Sage Publications.

Guerrero, E. G. (2013). Disparities in Latino substance use, service use, and treatment: Implications for culturally and evidence-based interventions under health care reform. Drug and Alcohol Dependence, 133(3), 805-813.

Guzman, M. (2005). Gay hegemony/Latino homosexualities. New York. Routledge.

Han, S. C.; Gallagher, M., Franz, M. R., Chen, M. S., Cabral, F., Marx, B. (2013). Childhood sexual abuse, alcohol use, and PTSD symptoms as predictors of adult sexual assault among lesbians and gay men. Journal of Interpersonal Violence, 28(12), 2505-2520.

Hankivsky, O. (2012). Women's health, men's health, and gender and health: Implications of intersectionality. Social Science \& Medicine, 74(11), 1712-1720.

Hansson, R. (1990). Adult children with frail elderly parents: When to intervene? Family Relations, 39(2), 153.

Hawkley, L. C., Thisted, R. A., Masi, C. M., \& Cacioppo, J. T. (2010). Loneliness Predicts Increased Blood Pressure: Five-Year Cross-Lagged Analyses in MiddleAged and Older Adults. Psychology and Aging, 25(1), 132-141.

Henderson, L. (2009). Between the two: Bisexual identity among African Americans. Journal of African American Studies (New Brunswick, N.J.), 13(3), 263-282.

Herek, G. M., Garnets, L. D. (2007). Sexual orientation and mental health. Annual Review of Clinical Psychology, 3(1), 353-375.

Higgins, A., Sharek, D., \& Glacken, M. (2016). Building resilience in the face of adversity: Navigation processes used by older lesbian, gay, bisexual and transgender adults living in Ireland. Journal of Clinical Nursing, 38, 98- 123.

Hinchliff, S., Gott, M. (2011). Seeking medical help for sexual concerns in mid- and later life: A review of the literature. Journal of Sex Research, 48(2/3), 106-117.

Hoonaard, D. K. (2009). Experiences of Living Alone: Widows' and Widowers' Perspectives. Housing Studies, 24(6), 737-753.

Huang, J. (2011). Trajectory of depression symptoms and related factors in later life: A population based study. Social support scale. Journal of Affective Disorders, 133(3), 49-508. 
Jay, K. (2000). Tales of the lavender menace: A memoir of liberation. New York: Basic Books.

Johnson, P. (1992). Silence equals death: The response to AIDS within communities of color. University of Illinois Law Review, 1992(4), 1075-1083.

Johnson, M. J., Jackson, N. C., Arnette, J. K., \& Koffman, S. D. (2005). Gay and lesbian perceptions of discrimination in retirement care facilities, Journal of Homosexuality, 49, 83-102.

Jost, J. T., Banaji, M. R., \& Nosek, B. A. (2004). A decade of system justification theory: Accumulated evidence of conscious and unconscious bolstering of the status quo. Political Psychology, 25(6), 881-919.

Kaplan, R. L. (2011). Analyzing the Impact of the New Health Care Reform Legislation on Older Americans. Elder Law Journal, 18, 201- 231

Kantor, M. (1998). Homophobia: Description, development, and dynamics of gay bashing. Westport, CT: Praeger.

Kaufman, S. R. (2009). Making Longevity in an Aging Society: Linking Ethical Sensibility and Medicare Spending. Medical Anthropology, 28, 317- 325.

Kaufman G. \& Chin, P. V. (2003). Is Ageism Alive in Date Selection among Men? Age Requests among Gay and Straight Men in Internet Personal Ads. The Journal of Men's Studies, 11, 225-235.

Kellogg, W. K. (2003). Courtenay, W. H. (2000). Constructions of masculinity and their influence on men's well-being: A theory of gender and health. Social Science \& Medicine, 50, 1385- 1401.

Kim, S. (2005). Using community-partnered participatory research to address health disparities in a Latino community. Journal of Professional Nursing, 21(4), 199209.

Kinsey, A. C., Pomeroy, W. B., \& Martin, C. E. (1998). Sexual behavior in the human male. Bloomington, Indiana. Indiana University Press.

King, J.L. (2004). On the Down Low: A Journey into the lives of straight black men who sleep with men. New York. Random House Inc.

Kornblum, W., \& Julian, J. (2012). Social problems. Upper Saddle River, New Jersey: Pearson. 
Knochel, K. A., Quam, J. K., \& Croghan, C. F. (2010). Are Old Lesbian and Gay People Well Served?: Understanding the Perceptions, Preparation, and Experiences of Aging Services Providers. Journal of Applied Gerontology, 30(3), 370-389.

Kurtz, S. P. (1999). Butterflies Under Cover: Cuban and Puerto Rican Gay Masculinities in Miami. Journal of Men's Studies, 7(3), 371-390.

Laverty, S. M. (2003). Hermeneutic Phenomenology and Phenomenology: A Comparison of Historical and Methodological Considerations. International Journal of Qualitative Methods, 2(3), 21-35.

Lincoln, Y. S., \& Guba, E. G. (1985). Naturalistic inquiry. Beverly Hills, CA: Sage Publications.

Loiacano, D. K. (1989). Gay Identity Issues Among Black Americans: Racism, Homophobia, and the Need for Validation. Journal of Counseling \& Development, 68(1), 21-25.

MacNaughton, N. S. (2008). Health disparities and health-seeking behavior among Latino men: A review of the literature. Journal of Transcultural Nursing, 19, 8391.

Markides, K. S., Angel, R. J., \& Peek, K. M. (2013). Aging, health, and families in the Hispanic population: Evolution of a paradigm. In M. Silverstein, \& R. Giarrusso (Eds.), Kinship and cohort in an aging society: From generation to generation. (pp. 314-332). Baltimore, MD: The John Hopkins University Press.

Marquez, B., Elder, J. P., Arredondo, E. M., Madanat, H., Ji, M., \& Ayala, G. X. (2014). Social network characteristics associated with health promoting behaviors among Latinos. Health Psychology, 33(6), 544-553.

Maxwell, J. A. (1996). Qualitative research design: An interactive approach. Thousand Oaks, CA: Sage Publications.

Mayer, K. H., Bradford, J. B., Makadon, H. J., Stall, R., Goldhammer, H., \& Landers, S. (2008). Sexual and Gender Minority Health: What We Know and What Needs to Be Done. American Journal of Public Health, 98(6), 989-995.

McParland, J., \& Camic, P. M. (2016). Psychosocial factors and ageing in older lesbian, gay and bisexual people: A systematic review of the literature. Journal of Clinical Nursing.

Mead, M. (1943). Coming of age in Samoa : A study of adolescence and sex in primitive societies. Harmondsworth, England: Penguin. 
Miller, D. L. (1980). George Herbert Mead: Self, language, and the world. Chicago: University of Chicago Press.

Miller Jr., R. L. (2007). Legacy Denied: African American Gay Men, AIDS, and the Black Church. Social Work, 52(1), 51-61.

Miller, W. (2014). Chronic neurological conditions and aging Americans: Implications for nursing. The Journal of Neuroscience Nursing, 46(5), 251- 252.

Mills, T. C., Paul, J., Stall, R., Pollack, L., Canchola, J., Y. Jason Chang, J., \& ... Catania, J. A. (2004). Distress and Depression in Men Who Have Sex with Men: The Urban Men's Health Study. American Journal of Psychiatry, 161(2), 278-285.

Monnin, J. (2012). Sociodemographic and psychopathological risk factors in repeated suicide attempts: Gender differences in a prospective study. Journal of Affective Disorders, 136(1-2), 35-43.

Moraga, C. (1993). The sexuality of Latinas. Berkeley. Third Woman Press.

Moses, H. (2013). The anatomy of health care in the United State. The Journal of the American Medical Association, 310(18), 1947-1963.

Myall, B. R., Hine, D. W., Marks, A. D., Thorsteinsson, E. B., Brechman-Toussaint, M., \& Samuels, C. A. (2009). Assessing individual differences in perceived vulnerability in older adults. Personality and Individual Differences, 46(1), 8-13.

National Council on Aging (2014). Fact Sheet: Health Aging. Retrieved from https://www.ncoa.org/news/resources-for-reporters/get-the-facts/healthy-agingfacts

National Hispanic Council on Aging (2013). Hispanic LGBT older adult needs assessment. Retrieved from http://www.nhcoa.org/wpcontent/uploads/2014/02/NHCOA-Hispanic-LGBT-Older-Adult-NeedsAssessment-In-Their-Own-Words.pdf

National Institute on Retirement Security (2010). The retirement saving crisis: Is it worse than we think ?Retrieved from:

http://www.nirsonline.org/index.php?option=content\&task=view\&id=768

Nemmers, T. M. (2004). The Influence of ageism and ageist stereotypes on the elderly. Physical \& Occupational Therapy in Geriatrics, 22(4), 11-20.

North, M. S., \& Fiske, S. T. (2012). An inconvenienced youth? Ageism and its potential intergenerational roots. Psychological Bulletin, 138(5), 982-997. 
Okello, E., Wagner, G., Ghosh-Dastidar, B., Garnett, J., Akena, D., Nakasujja, N., Musisi S. (2015). Depression, internalized HIV stigma and HIV disclosure. World Journal of AIDS, 5, 30-40.

Osmanovic-Thunström, A., Mossello, E., Åkerstedt, T., Fratiglioni, L., \& Wang, H. (2015). Do levels of perceived stress increase with increasing age after age 65? A population-based study Age Ageing, 44, 828-834.

Pascoe, C. J. (2007). Dude, you're a fag: Masculinity and sexuality in high school. Berkeley: University of California Press.

Patterson, C. J. (2000). Family Relationships of Lesbians and Gay Men. Journal of Marriage \& Family, 62(4), 1052-1069.

Paulhaus D.L. (2002). Socially desirable responding: The evolution of a construct. In H.I. Braun., D.N. Jackson (Eds.), The role of constructs in psychological and educational measurement (pp. 37-48). Mahwah, NJ: Erlbaum.

Peralta, C. A., Lee, A., Odden, M. C., Lopez, L., Hazzouri, A. Z. A., Neuhaus, J., \& Haan, M. N. (2013). Association between chronic kidney disease detected using creatinine and cystatin $\mathrm{C}$ and death and cardiovascular events in elderly Mexican Americans: The Sacramento area Latino study on aging. Journal of the American Geriatrics Society, 61(1), 90-95.

Purdie-Vaughns, V., \& Eibach, R. P. (2008). Intersectional Invisibility: The Distinctive Advantages and Disadvantages of Multiple Subordinate-Group Identities. Sex Roles, 59(5-6), 377-391.

Ragins, B. R., Singh, R., \& Cornwell, J. M. (2007). Making the invisible visible: Fear and disclosure of sexual orientation at work. Journal of Applied Psychology, 92(4), 1103-1118.

Reiss, I. L., Reiss, H. M., \& Reiss, I. L. (1997). Solving America's sexual crises. Amherst, N.Y: Prometheus Books.

Reisen, C. A., Zea, M. C., Bianchi, F. T., Poppen, P. J., Shedlin, M. G., \& Penha, M. M. (2010). Latino Gay and Bisexual Men's Relationships with Non-Gay-Identified Men Who Have Sex with Men. Journal of Homosexuality, 57(8), 1004-1021.

Reyes-Ortiz, C. A., Ayele, H., Mulligan, T., Espino, D. V., Berges, I. M., \& Markides, K. S. (2006). Higher church attendance predicts lower fear of falling in older Mexican-Americans. Aging \& Mental Health, 10(1), 13-18. 
Reyes-Ortiz, C. A., Berges, I. M., Raji, M. A., Koenig, H. G., Kuo, Y., \& Markides, K. S. (2008). Church Attendance Mediates the Association Between Depressive Symptoms and Cognitive Functioning Among Older Mexican Americans. The Journals of Gerontology Series A: Biological Sciences and Medical Sciences, 63(5), 480-486.

Robinson, B. A. (2015). The Quantifiable-Body Discourse: Height-Weight Proportionality and Gay Men's Bodies in Cyberspace. Social Currents, 3, 172185.

Robinson, S. J., Johnson, J. R., \& Rich, M. D. (2015). Inviting the Breach: Confronting Homophobia in the Name of Social Justice. Journal of Homosexuality, 62(7), 902-923.

Rosenfeld, D., Bartlam, B., \& Smith, R. D. (2012). Out of the Closet and Into the Trenches: Gay Male Baby Boomers, Aging, and HIV/AIDS. The Gerontologist, 52(2), 255-264.

Ruggiero, K. M., \& Taylor, D. M. (1997). Why minority group members perceive or do not perceive the discrimination that confronts them: The role of self-esteem and perceived control. Journal of Personality and Social Psychology, 72(2), 373-389.

Rupp, L. J. (1999). A desired past: A short history of same-sex love in America. Chicago: University of Chicago Press.

Sabogal, F., Marín, G., Otero-Sabogal, R., Marín, B., \& Pérez-Stable, E. J. (1987). Hispanic familism and acculturation: What changes and what doesn't? Hispanic Journal of Behavioral Sciences, 9, 397-412.

Sasson, I., \& Umberson, D. J. (2014). Widowhood and Depression: New Light on Gender Differences, Selection, and Psychological Adjustment. The Journals of Gerontology Series B: Psychological Sciences and Social Sciences, 69B(1), 135145 .

Schope, R. D. (2005). Who's Afraid of Growing Old? Journal of Gerontological Social Work, 45(4), 23-39.

Sidanius, J., \& Pratto, F. (1999). Social dominance: An intergroup theory of social hierarchy and oppression. Cambridge, UK: Cambridge University Press.

Simons- Morton, B. G., Haynie, D., \& Noelcke, E. (2009). Social influences: The effects of socialization, selection, and social normative processes on health behaviors. In R. DiClemente, R. Crosby \& M. Kegler (Eds.) Emerging theories in health promotion practice and research. (p. 65- 95) San Francisco, CA: Jossey- Bass. 
Singh, A., \& Misra, N. (2009). Loneliness, depression and sociability in old age. Indian Psychiatry Journal, 18(1), 51- 55.

Skinner, J. (2007). Are You Sure You're Saving Enough for Retirement? The Journal of Economic Perspectives, 21, 59-80.

Sneed, R. S., \& Cohen, S. (2014). Negative social interactions and incident hypertension among older adults. Health Psychology, 33(6), 554-565.

Stone, T., \& McMinn, B. (2012). What's in a word? Ageism: The bias against older people by the (temporarily) young?'. Nursing \& Health Sciences, 14(4), 433-434.

Strauss, A. L., \& Corbin, J. M. (1990). Basics of qualitative research: Grounded theory procedures and techniques. Newbury Park, CA: Sage Publications.

Thompson, E. (2015). Compromising equality: An analysis of the religious exemption in the employment non-discrimination act and its impact on LGBT workers. Boston College Journal of Law \& Social Justice, 35(2), 285-318.

Tomaka, J. (2006). The Relation of Social Isolation, Loneliness, and Social Support to Disease Outcomes Among the Elderly. Journal of Aging and Health, 18(3), 359384.

U.S. Census Bureau. (2006). U.S. 2005-2007 American community survey 3-Year Estimates. Retrieved from http,//factfinder.census.gov/home/saff/main.html?_lang=en

U.S. Census Bureau. (2014). Summary health Statistics for U.S. Adults: National Health Interview Survey. Retrieved from http://familiesusa.org/product/latino-healthdisparitiescompared-non-hispanic-whites\#sthash.7b3SM2It.dpuf

U.S. Department of Defense. (2015). Quick reference guide repeal of DADT. Retrieved from http://archive.defense.gov/home/features/2010/0610_dadt/Quick_Reference_Guid e_epeal_of_DADT_APPROVED.pdf

U. S. Department of Labor Statistics. (2008). BLS spotlight on statistics: Older workers. Retrieved from: https://stats.bls.gov/spotlight/2008/older_workers/pdf/older_workers_bls_spotligh t.pdf

U.S. Federal Bureau of Investigation. (2014). Uniform hate crimes report. Retrieved from https://www.fbi.gov/about-us/cjis/ucr/hate-crime/2014/topic-pages/victims_final

U.S. Health and Human Services. (2014). Vital and health statistics. Retrieved from http://www.hhs.gov 
Vaismoradi, M., Turunen, H., \& Bondas, T. (2013). Content analysis and thematic analysis: Implications for conducting a qualitative descriptive study. Nursing \& Health Sciences, 15, 398-405.

Vega, W. A. (2011). Neighborhood protective effects on depression in Latinos. American Journal of Community Psychology, 47, 114-126.

Wallace, S. P., Cochran, S. D., Durazo, E. M., \& Ford, C. L. (2011). The Health of Aging Lesbian, Gay and Bisexual Adults in California- Policy Brief. UCLA Center for Health Policy Research.

Wilkin, H. A. \& Ball-Rokeach, S.J. (2006). Reaching at risk groups: The importance of health storytelling in Los Angeles Latino media. Journalism, 7(3), 299-320.

Williams, D. R., \& Mohammed, S. A. (2008). Discrimination and racial disparities in health: Evidence and needed research. Journal of Behavioral Medicine, 32(1), 2047.

Wu, A. M. (2004). Physical and Psychosocial Factors Associated with Health-promoting Behaviors among Elderly Chinese with Type-2 Diabetes. Journal of Health Psychology, 9(6), 731-740. 


\section{TABLES}

Table 1. Study Participant Demographics

\begin{tabular}{|c|c|c|c|c|}
\hline & Total $(N$ & & & \\
\hline Demographics & $n$ & $\%$ & Range & Mean \\
\hline Ethnicity & & 100.0 & & \\
\hline Hispanic & 20 & 100.0 & & \\
\hline Age & 20 & 100.0 & $50-70$ years & 58 \\
\hline Education & 20 & 100.0 & & \\
\hline$<$ High School & 1 & $5 \%$ & & \\
\hline High School & 12 & $60 \%$ & & \\
\hline College (secondary) & 5 & $25 \%$ & & \\
\hline Graduate (postsecondary) & 2 & $10 \%$ & & \\
\hline Employment & 20 & 100.0 & & \\
\hline Part-time & 11 & $55 \%$ & & \\
\hline Full-time & 3 & $15 \%$ & & \\
\hline Self-employed & 1 & $5 \%$ & & \\
\hline Retired & 5 & $25 \%$ & & \\
\hline Retirement plan & 20 & & & \\
\hline Yes & 3 & $15 \%$ & & \\
\hline No & 17 & $85 \%$ & & \\
\hline Health insurance coverage & 20 & & & \\
\hline Yes & 16 & $80 \%$ & & \\
\hline No & 4 & $20 \%$ & & \\
\hline Length of time in U.S. & 20 & 100.0 & & \\
\hline Less than 1 year & 1 & $5 \%$ & & \\
\hline 1 to 2 years & 4 & $20 \%$ & & \\
\hline $3-4$ years & 9 & $45 \%$ & & \\
\hline 5 years or more & 6 & $30 \%$ & & \\
\hline Country of origin & 20 & 100.0 & & \\
\hline Colombia & 2 & $10 \%$ & & \\
\hline Cuba & 8 & $40 \%$ & & \\
\hline Mexico & 3 & $15 \%$ & & \\
\hline Puerto Rico & 3 & $15 \%$ & & \\
\hline Venezuela & 1 & $5 \%$ & & \\
\hline U.S. & 3 & $15 \%$ & & \\
\hline
\end{tabular}




\begin{tabular}{|c|c|c|}
\hline County of residence & 20 & $100 \%$ \\
\hline Miami Dade County & 2 & $10 \%$ \\
\hline \multirow[t]{2}{*}{ Broward County } & 18 & $90 \%$ \\
\hline & 20 & 100.0 \\
\hline \multicolumn{3}{|l|}{ Living arrangements } \\
\hline Living alone & 16 & $80 \%$ \\
\hline Living with a partner & 4 & $20 \%$ \\
\hline Partnered/committed relationship & 20 & 100.0 \\
\hline Yes & 6 & $30 \%$ \\
\hline No & 14 & $70 \%$ \\
\hline $\begin{array}{l}\text { Mother's knowledge of subject's } \\
\text { orientation }\end{array}$ & 20 & 100.0 \\
\hline Mother knows & 15 & $75 \%$ \\
\hline Mother does not know & 5 & $25 \%$ \\
\hline Not sure & 0 & \\
\hline $\begin{array}{l}\text { Father's knowledge of subject's } \\
\text { orientation }\end{array}$ & 20 & 100.0 \\
\hline Father knows & 5 & $25 \%$ \\
\hline Father does not know & 12 & $60 \%$ \\
\hline Not sure & 3 & $15 \%$ \\
\hline $\begin{array}{l}\text { Siblings' knowledge of subject's } \\
\text { sexual orientation }\end{array}$ & 20 & 100.0 \\
\hline Siblings know & 16 & $80 \%$ \\
\hline Siblings do not know & 3 & $15 \%$ \\
\hline Not sure & 1 & $5 \%$ \\
\hline $\begin{array}{l}\text { Extended family's knowledge of } \\
\text { subject's sexual orientation }\end{array}$ & 20 & 100.0 \\
\hline Yes & 5 & $25 \%$ \\
\hline No & 15 & $75 \%$ \\
\hline Not sure & 0 & $0 \%$ \\
\hline Children & 20 & 100.0 \\
\hline Yes & 1 & $5 \%$ \\
\hline No & 19 & $95 \%$ \\
\hline HIV Status & 20 & 100.0 \\
\hline HIV positive & 7 & $35 \%$ \\
\hline HIV negative & 10 & $50 \%$ \\
\hline Status unknown & 3 & $15 \%$ \\
\hline
\end{tabular}




\section{APPENDICES}

\section{Appendix A: Consent Form}

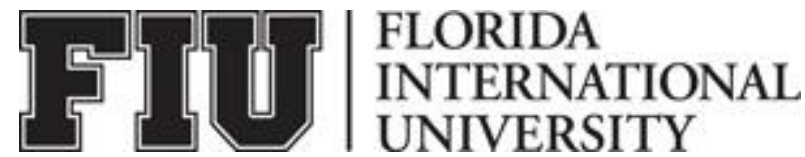

\section{ADULT VERBAL CONSENT TO PARTICIPATE IN A RESEARCH STUDY}

Adult Hispanic Male Health Study

Hello, our names are Victor Chris Vila and Dr. Dionne Stephens. You have responded to our recruitment flyer seeking people to be in a research study about health and aging beliefs among men. The purpose of the current study is to examine perceptions of health and aging among adult Hispanic gay/ bisexual men, ages 50 through 70 in South Florida. If you decide to be in the current study, you will be one of 25 men in this research study. Participation in the current study will take no more than 90 minutes of your time. If you agree to be in the study, I will ask you to do the following things:

1. Complete a survey. You will be asked to complete a survey with questions related to your thoughts and feelings about health and community related questions. This should take about 15-20 minutes. The hardcopy survey will be completed with pen/pencil. No personal identifying information will be asked in the survey.

2. Be Interviewed. You will be asked questions about your thoughts, experiences, concerns and feelings about health and community related topics. The interview will take about 30 to 40 minutes. The interview will be recorded but this is for our records. No personal identifiers will be used during the interview. The recorded files will be kept in a secure password protected file.

There are no foreseeable risks or benefits to you for participating in the current study. Some questions in this interview and survey will ask about your general health, perceptions of aging and social/ relationship experiences which may cause you some discomfort. It is expected that the current study will benefit society by providing information about a group that is understudied and underserved. Second, participating in the current study will help you reflect on yourself and your health

There is no cost to you. You will receive at $\$ 10$ gift card to compensate you for your time. You may withdraw your participation at any time during the study and you will still receive a $\$ 10.00$ gift certificate. If you have questions while taking part, please stop me and ask.

You will remain anonymous as you are not signing any forms and we are asking that you provide a pseudonym/ fake name for use during your interview. In any sort of report we 
might publish, we will not include any information that will make it possible to identify you as a subject as you will be referred to using the pseudonym/ fake name you have provided. Research records will be stored securely and only we will have access to the records.

Again, your participation in the current study is voluntary. You are free to participate in the study or withdraw your consent at any time during the study. Your withdrawal or lack of participation will not affect any benefits to which you are otherwise entitled.

This research, like all human subjects research at the University, was reviewed by the Institutional Review Board to ensure ethical treatment of participants. If you have any questions about the current study, please do not hesitate to contact us [Dr. Dionne Stephens (stephens@fiu.edu, 305-348-1809) or Chris Vila (vv001@ fiu.edu, 305- 7330010); DM 203; 11200 SW 8th Street, Miami, 33199]

If you would like to speak with someone about your rights as a volunteer in this research study, you may contact you may contact the FIU Office of Research Integrity by phone at 305-348-2494 or by email at ori@fiu.edu

If you choose not to participate, you may leave now or indicate to the interviewer that you do not wish to proceed when asked. Your participation in this research is voluntary, and you will not be penalized or lose benefits if you refuse to participate or decide to stop. Do you consent to participate in this project?

\section{*You may keep this document for your records.}




\section{Appendix B. Demographic Questionnaire}

\section{Basic Demographic Questions}

What is the zip code for the neighborhood where you currently live?

What is your year of birth?

What country were you born in?

Where do you consider "home"?

How many years have you lived in the United States?

Do you have children?

Yes (1)

No (2)

If No Is Selected, Then Skip To What is the highest level of education...

What are the ages of your children?

What is the highest level of education you have completed?

Some high school (1)

High school Diploma (2)

Some College (3)

Associates Degree (4)

Bachelors Degree (5)

Masters Degree (6)

Doctoral Degree (7)

Other (Please write in your answer) (8)

What is your current employment status?

Working outside the home full time (1)

Working outside the home part time (2)

Currently not working due to unemployment (3)

Retired (4)

Other (please write in your answer) (5)

What kind of work do/ did you do?

Which of the following describes you? (select all that apply)

Gay (1) 
Bisexual (2)

MSM (Men who have sex with Men) (3)

Other (4)

Take time to think about who you are attracted to. Consider your preferred sexual partners, fantasies, dreams, and practices. Now select which of the options below best describes these.

Exclusively heterosexual (1)

Predominantly heterosexual/incidentally homosexual (2)

Predominantly heterosexual/more than incidentally homosexual (3)

Equally heterosexual and homosexual (4)

Predominantly homosexual/more than incidentally heterosexual (5)

Predominantly homosexual/incidentally heterosexual (6)

Exclusively homosexual/ gay (7)

Do you know your HIV/AIDS status?

(Please circle one)

Yes

No

Not sure

When was the last time you had sex with a male?

When I have sex I wear condoms ?

(Please circle one)

Yes

No

Sometimes

When I have sex, my partner/s wear/s condoms?

(Please circle one)

Yes

No

Sometimes

What is your HIV/AIDS status?

(Please circle one)

$\mathrm{HIV+}$

HIV-

Don't know 
When was the last time you were tested for HIV/AIDS?

(Please enter the date or enter never if you have not been tested).

Does/ did your mother know about your orientation?

Yes (1)

No (2)

Does/ did your father know about your orientation?

Yes (1)

No (2)

Do/did sibling/s know about your orientation?

Yes (1)

No (2)

Do people in your extended family (Aunts, Uncles, or Cousins) know about your orientation?

Yes (1)

$\square \quad$ No (2) 


\section{Appendix C: Questioning Route}

Time Started

Participant

\#

1. What is aging like for you as a gay male?

Probes: Health care provider relationships, personal relationships, social network, community needs, services, psycho-social adaption to aging, independence.

2. Tell me about your experiences related to aging that you think have been affected by you identifying as a gay male.

Probes: Health care provider relationships, personal relationships, social network, community needs, services, psycho-social adaption to aging, independence.

3. What are your concerns for the immediate future?

Probes: Partner situation, social networks, health

4. What is likely to make your transition to older age easier or harder?

Probes: Partner situation, social networks, health

5. Tell me about your retirement.

Probes: Are you retired? Do you plan on retiring? If you are retired what has changed since?

6. When you think about getting older, what concerns come to mind?

Probes: Living arrangements, need for long-term care, medical/legal issues? 